\title{
How Surface Species Drive Product Distribution during Ammonia Oxidation: An STM and Operando APXPS Study
}

Oleksii Ivashenko,* Niclas Johansson, Christine Pettersen, Martin Jensen, Jian Zheng, Joachim Schnadt, and Anja O. Sjåstad*

Cite This: ACS Catal. 2021, 11, 8261-8273

Read Online

\section{ACCESS 1}

Џlll Metrics \& More

Article Recommendations

Supporting Information

ABSTRACT: The oxidation of ammonia is a key reaction for the production of artificial fertilizers and for environmental protection. Depending on the area of application, the catalytic reaction needs to be tuned toward the production of either $\mathrm{N}_{2}$ or NO, and this selectivity is controlled by temperature, pressure, reactant ratio, and the type of catalyst. PtRh alloys are highly useful catalytic materials for the oxidation of ammonia, and they can be employed at different reaction conditions. In contrast to pure $\mathrm{Pt}$ and $\mathrm{Rh}$ catalysts, for which a large number of studies of ammonia oxidation reaction mechanism are available, for $\mathrm{PtRh}$ alloys, direct spectroscopic evidence for structure-performance relationship is still lacking. To understand the behavior of PtRh alloys, namely, what is their active phase under reaction conditions and how the alloy composition leads to a particular product distribution, we study the oxidation of ammonia over $\mathrm{PtRh} / \mathrm{Pt}(111)$ surfaces by simultaneous operando ambient pressure X-ray photoelectron spectroscopy and mass spectrometry at $1 \mathrm{mbar}$ total reaction pressure. These data are complemented by a catalyst surface characterization by scanning tunneling microscopy in ultrahigh vacuum. We establish that the predominant surface structure during $\mathrm{NH}_{3}$ oxidation strongly depends on the degree of Pt enrichment and the $\mathrm{O}_{2} / \mathrm{NH}_{3}$ mixing ratio. At the nanoscale, the selectivity toward $\mathrm{N}_{2}$ or $\mathrm{NO}$ production is driven by the surface populations of $\mathrm{N}$ and $\mathrm{O}$ species. These, in turn, are controlled by the nature of the alloying of $\mathrm{Pt}$ with $\mathrm{Rh}$.

KEYWORDS: $\mathrm{NO}_{x}$ abatement, ammonia slip catalysis, operando measurements, APXPS, Pt(111), platinum, rhodium, surface alloy

\section{INTRODUCTION}

Ammonia oxidation is an essential catalytic reaction used in the production of artificial fertilizers and in environmental applications. In both these cases, particular focus is on two products of the reaction, namely, $\mathrm{NO}$ and $\mathrm{N}_{2}$ (cf. eqs $1-2$ ). The selectivity toward either one is dictated by reaction parameters, that is, by temperature, $\mathrm{O}_{2} / \mathrm{NH}_{3}$ partial pressures, and the type of catalyst. Regarding these parameters, the two following regimes can be distinguished: on the one hand, the formation of $\mathrm{NO}$ is the first stage of the Ostwald process (cf. eq 1), which uses NO for subsequent production of nitric acid and fertilizers. Here, high temperature and an $\mathrm{O}_{2} / \mathrm{NH}_{3}$ ratio of (65:35) in nitrogen are employed. On the other hand, the intermediate-temperature oxidation of ammonia is essential for $\mathrm{NO}_{x}$ abatement, in which environmental catalysis targets $\mathrm{N}_{2}$ as the main product (eq 2). ${ }^{1}$ Here, unreacted ammonia from the selective catalytic reduction (SCR) unit is selectively oxidized to $\mathrm{N}_{2}$ (eq 2). This reaction is frequently denoted as the ammonia "slip" oxidation and conducted in a typical $\mathrm{O}_{2} / \mathrm{NH}_{3}$ ratio of (99:1). The formation of $\mathrm{N}_{2} \mathrm{O}$ (eq 3) is undesired for both the described applications.

$$
\begin{aligned}
& 4 \mathrm{NH}_{3}+5 \mathrm{O}_{2} \rightarrow 4 \mathrm{NO}+6 \mathrm{H}_{2} \mathrm{O} \\
& 4 \mathrm{NH}_{3}+3 \mathrm{O}_{2} \rightarrow 2 \mathrm{~N}_{2}+6 \mathrm{H}_{2} \mathrm{O}
\end{aligned}
$$

$$
4 \mathrm{NH}_{3}+4 \mathrm{O}_{2} \rightarrow 2 \mathrm{~N}_{2} \mathrm{O}+6 \mathrm{H}_{2} \mathrm{O}
$$

For ammonia oxidation at Ostwald process conditions, catalytically efficient bimetallic PtRh gauzes have been used and studied for decades. ${ }^{2}$ Insights into the elementary reaction steps on the alloyed gauzes have been gained from a number of $\mathrm{Pt}$ and $\mathrm{Rh}$ model surface investigations at gas mixing conditions typical for the Ostwald process. ${ }^{3-10}$ In contrast, alloyed model PtRh surfaces, for which Rh surface segregation occurs in an oxidative environment, ${ }^{11}$ remain largely unexplored in this context. Likewise, despite the great importance of ammonia oxidation for environmental catalysis, little is known about the formation of $\mathrm{N}_{2}$ and $\mathrm{NO}$ products at conditions relevant for $\mathrm{NH}_{3}$ "slip" oxidation, that is, intermediate temperature $(550-650 \mathrm{~K})$ and pressure of 0.1 bar $\mathrm{O}_{2}+0.001$ bar $\mathrm{NH}_{3}$, corresponding to a high oxygen excess ratio of (99:1).

Received: March 1, 2021

Revised: June 7, 2021

Published: June 21, 2021 
a)

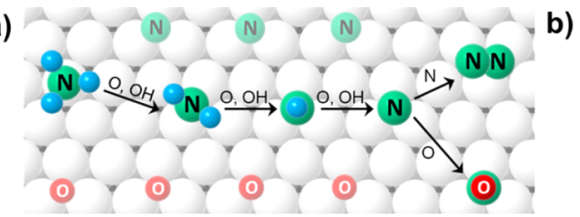

b)

\begin{tabular}{|c|c|c|}
\hline $\mathrm{NH}_{3} \stackrel{5000 / k}{\longrightarrow} \mathrm{NH}_{2}+\mathrm{H}^{+}$ & (4) & \\
\hline $\mathrm{H}_{\mathrm{x}}+\mathrm{OH} \rightarrow \mathrm{NH}_{\mathrm{x}-1}+\mathrm{H}_{2} \mathrm{O}$ & (5) & \\
\hline $\mathrm{H}_{3}+\mathrm{O} \rightarrow \mathrm{NH}_{2}+\mathrm{OH}$ & (6) & \\
\hline$H_{x}+\mathrm{O} f \mathrm{NH}_{x-1}+\mathrm{OH}$ & (7) & \\
\hline
\end{tabular}

Figure 1. (a) Stepwise dehydrogenation of $-\mathrm{NH}_{3}$ (adsorbed on top) to $-\mathrm{NH}_{2}$ (bridge), $-\mathrm{NH}$ (hollow fcc), and atomic $-\mathrm{N}$ (hollow fcc) on $\mathrm{Pt}(111)$, assisted by surface $-\mathrm{O}$ (hollow fcc) and $-\mathrm{OH}$ (bridge, not shown) species, based on the mechanism described in ref 14. Main product formation is a recombination reaction between $-\mathrm{N}$ and either another $-\mathrm{N}$ or $-\mathrm{O}$, resulting in $\mathrm{N}_{2}$ and $\mathrm{NO}$, respectively. (b) On $\mathrm{Pt}(111)$ and $\mathrm{Rh}(111)$ surfaces, unassisted dehydrogenation is not observed below $600 \mathrm{~K}$ (eq 4), and $\mathrm{NH}_{3}$ can be activated by surface $-\mathrm{OH}$ (eq 5). In addition, oxygen can activate initial deprotonation of $\mathrm{NH}_{3}$ on $\mathrm{Pt}(111$ ) (eq 6), while the subsequent oxygen-mediated deprotonations are not favored (eq 7)..$^{14,15}$

The kinetics and mechanism of $\mathrm{NH}_{3}$ oxidation on $\mathrm{Pt}$ surfaces are well described in the works of Bradley et al. ${ }^{12}$ and Kraehnert and Baerns. ${ }^{13}$ In brief, stepwise dehydrogenation of $\mathrm{NH}_{3}$ via reaction with co-adsorbed atomic oxygen yields atomic $-\mathrm{N}$ species (Figure 1a). Then, recombination with another $-\mathrm{N}$ or $-\mathrm{O}$ produces, respectively, the major product $\mathrm{N}_{2}$ or $\mathrm{NO}$, activity and selectivity to which are dictated by $-\mathrm{O}$ and $-\mathrm{N}$ adsorption strength, coverages, and reaction barriers. These were provided by density functional theory calculations for $\operatorname{Pt}(111)^{14}$ and $\operatorname{Rh}(111) .{ }^{15}$ In both cases, the most stable surface species are $-\mathrm{N},-\mathrm{NH}$, and $-\mathrm{O}$, all of which have a strong preference for adsorption in fcc surface sites of $\mathrm{Pt}(111)$ (Figure 1a). The $\mathrm{NH}_{3}$ activation patterns on the $\mathrm{Pt}(111)$ and $\mathrm{Rh}$ (111) surfaces share two commonalities: (i) on both surfaces, unassisted $\mathrm{NH}_{3}$ dissociation has a high activation barrier and has not been observed experimentally below $600 \mathrm{~K}$ (eq 4 in Figure 1b) and (ii) on both surfaces, the attraction between $-\mathrm{OH}$ and all $-\mathrm{NH}_{x}$ species results in a lowering of the energy barrier for all deprotonation steps (eq 5). The main distinction lies in the role of oxygen in the deprotonation of $\mathrm{NH}_{3}$. On $\mathrm{Rh}(111)$, the $\mathrm{NH}_{3}$ activation is not affected by the presence of $-\mathrm{O}$ surface species but requires $-\mathrm{OH}$ surface species. In contrast, on $\mathrm{Pt}(111),-\mathrm{O}$ surface species are essential for the first deprotonation of $\mathrm{NH}_{3}$ to $\mathrm{NH}_{2}$ (eq 6). For further deprotonation of $\mathrm{NH}_{2}$ and $\mathrm{NH}$, they do not play any role (eq 7). ${ }^{14-17}$ These two findings together suggest that an $-\mathrm{O} /-\mathrm{OH}$ synergy might be found in the $\mathrm{NH}_{3}$ activation over PtRh alloys.

Further experimental single-crystal studies on $\operatorname{Pt}(111),{ }^{16}$ $\operatorname{Pt}(443),{ }^{3,10} \mathrm{Pt}(533),{ }^{9,18,19} \mathrm{Pt}(410),{ }^{8} \mathrm{Rh}(110),{ }^{5}$ and PtRh bulk alloys $^{20}$ have explored how the reactant pressure, temperature, and reactants mixing ratio affect the reaction. These studies agree that near-stoichiometric (50:50) gas mixtures of $\mathrm{O}_{2}$ and $\mathrm{NH}_{3}$ in a wide pressure range of $10^{-6}$ mbar to a few bars and a temperature below $700-800 \mathrm{~K}$ always lead to the formation of $\mathrm{N}_{2}$ as the main product. ${ }^{16}$ For $\mathrm{Pt}(410)$, Weststrate et al. showed that the selectivity toward $\mathrm{N}_{2}$ or $\mathrm{NO}$ in the oxidation of ammonia is determined by the surface coverage. ${ }^{8}$ Depending on the $-\mathrm{N}$ and $-\mathrm{O}$ surface population, three regimes could be distinguished: when the surface is $\mathrm{NH}_{x} / \mathrm{N}$-covered, the reaction product is mainly $\mathrm{N}_{2}$; when the surface is O-covered, $\mathrm{NO}$ is the major product; and $\mathrm{N}_{2} \mathrm{O}$ forms when $\mathrm{N}$ and $\mathrm{NO}$ coexist on the surface. Conditions that favor $\mathrm{N}$-covered surfaces include a low total pressure $\left(10^{-4} \mathrm{mbar}\right){ }^{19}$ which allows for rapid decomposition of $\mathrm{NH}_{3}$ and consumption of $-\mathrm{O}$, and intermediate temperature $(<650 \mathrm{~K})$, which facilitate slow (rate-limiting) desorption of the produced $\mathrm{N}_{2}$. Conversely, an O-covered surface can be achieved by the use of higher pressure (in the mbar range) and higher temperature, ${ }^{5}$ at which oxygen is significantly more stable than $\mathrm{N}$-based products. At realistic reaction conditions of 1 bar and above, Pt and $\mathrm{Rh}$ can form surface and bulk oxides and, therefore, reactivity and selectivity to various products will differ greatly from those observed for metallic Pt and Rh single crystals. For instance, already at $1 \mathrm{mbar} \mathrm{O}_{2}, \mathrm{Rh}(111)$ will form a $\mathrm{RhO}_{2}$ surface oxide trilayer $(\mathrm{O}-\mathrm{Rh}-\mathrm{O}),{ }^{21,22}$ which is an inactive phase for $\mathrm{CO}$ oxidation. ${ }^{23,24}$

The question is now to which extent the above findings also apply to alloys of $\mathrm{Pt}$ and $\mathrm{Rh}$ and how the two different alloy components work together in the oxidation of ammonia at different gas mixing and alloy component ratios. To address this, here we report an operando ambient-pressure X-ray photoelectron spectroscopy (APXPS) study of ammonia oxidation at $1 \mathrm{mbar}$ and $600 \mathrm{~K}$ over several different $\mathrm{Rh} /$ $\mathrm{Pt}(111)$ and $\mathrm{Pt}(111)$ surfaces. By varying the $\mathrm{O}_{2}$ and $\mathrm{NH}_{3}$ mixing ratio (50:50 and 99:1) at $600 \mathrm{~K}$, we explore spectroscopic details relevant for the Ostwald process and $\mathrm{NH}_{3}$ "slip" oxidation, respectively. The range of $\mathrm{Rh}$ coverage (0.4-1.2 ML) prepared on $\mathrm{Pt}(111)$ allows the investigation of how $\mathrm{Rh}$ enrichment and degree of $\mathrm{Pt}-\mathrm{Rh}$ alloying influences the product distribution. From an analysis of the surface species $\left(\mathrm{O}, \mathrm{N}, \mathrm{NO}\right.$, and $\left.\mathrm{H}_{2} \mathrm{O}\right)$ and gas species $\left(\mathrm{N}_{2}, \mathrm{NO}, \mathrm{H}_{2} \mathrm{O}\right.$, and $\mathrm{N}_{2} \mathrm{O}$ ) observed in XPS and quadrupole mass spectroscopy (QMS), we address the question of predominant phases of $\mathrm{Rh}$ and $\mathrm{Pt}$. We conclude with an apparent link between the $\mathrm{O}_{2} /$ $\mathrm{NH}_{3}$ mixing ratio, degree of $\mathrm{Pt}-\mathrm{Rh}$ alloying, and adsorbate coverage, which determine reaction product distribution.

\section{EXPERIMENTAL DETAILS}

Sample Preparation. A Pt(111) single crystal (obtained from Surface Preparation Laboratory) was cleaned in repetitive cycles of $\mathrm{Ar}^{+}$sputtering with an energy of $1 \mathrm{kV}$ for $10 \mathrm{~min}$ and annealing at $1150 \mathrm{~K}$ in both $\mathrm{O}_{2}\left(5 \times 10^{-7} \mathrm{mbar}, 2 \mathrm{~min}\right)$ and ultrahigh vacuum (UHV, $5 \mathrm{~min}$ ). The crystal quality in terms of cleanness, crystallinity, and flatness was verified by means of XPS, low-energy electron diffraction (LEED), and scanning tunneling microscopy (STM). Rhodium (99.9\%, Goodfellow) was subsequently deposited onto the $\mathrm{Pt}(111)$ single crystal using an e-beam evaporator. The depositions were done at 375 $\mathrm{K}$ in UHV at a pressure less than $2 \times 10^{-9}$ mbar, using a flux of $0.08 \mathrm{ML} / \mathrm{min}$ for $4-15 \mathrm{~min}$, as estimated from combined XPS and STM data in a previous study. ${ }^{25}$ After every experiment, at least four cleaning cycles were performed to ensure a pristine $\mathrm{Pt}(111)$ surface. After post-annealing, trace amounts of carbon and oxygen were found on the surface. During oxidation at 1 mbar $\mathrm{O}_{2}$ at $600 \mathrm{~K}$ as well as during subsequent $\mathrm{NH}_{3}$ oxidation, no $\mathrm{C}$ was found at the surface. No other contaminations were detected at the surface as prepared. After operando studies, no sign of surface reconstruction ${ }^{16,26}$ was found in post-mortem LEED and STM (Figures S8 and S9). 

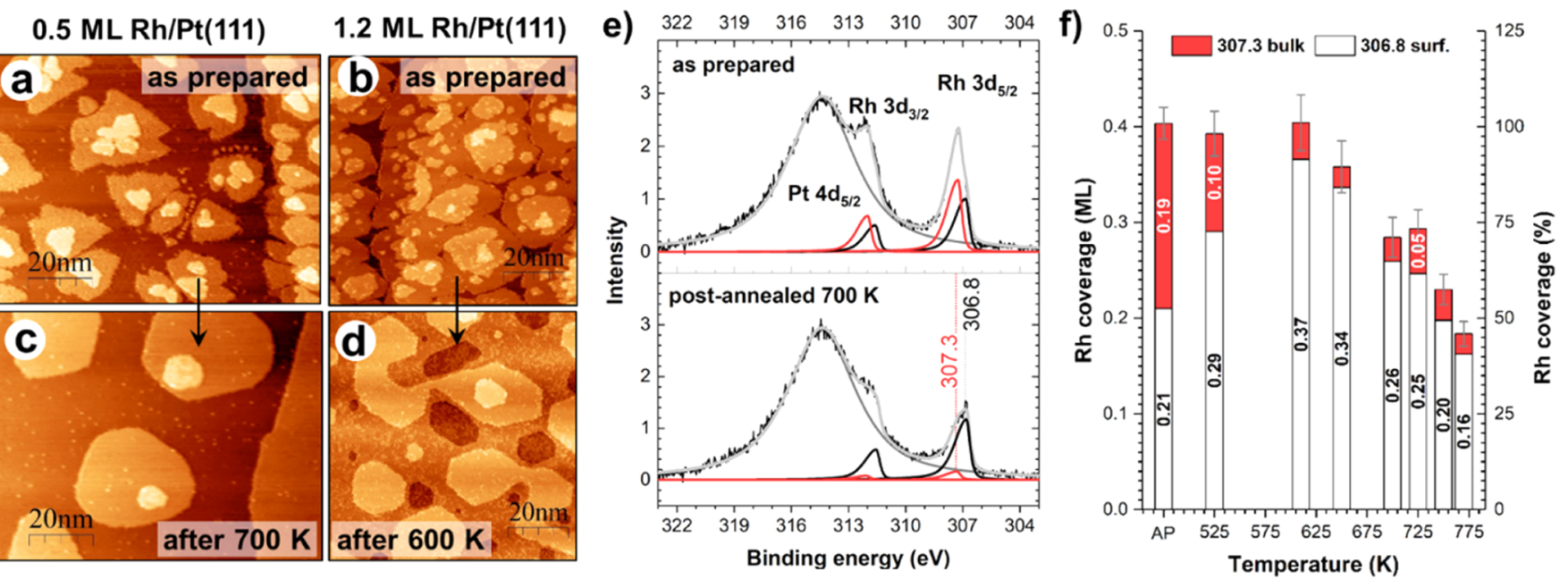

Figure 2. STM morphology of (a) 0.5 and (b) $1.2 \mathrm{ML} \mathrm{Rh/Pt(111)} \mathrm{as} \mathrm{prepared} \mathrm{at} 375 \mathrm{~K}$ and post-annealed to (c) 700 and (d) $600 \mathrm{~K} ; U_{\mathrm{t}}=-0.5 \mathrm{~V}$, $I_{t}=-0.2 \mathrm{nA}$. The as-prepared morphology features three incomplete Rh layers, which after post-annealing form continuous domains. (e) UHV XP spectra collected as prepared and after post-annealing of $0.5 \mathrm{ML} \mathrm{Rh} / \mathrm{Pt}(111)$ to $700 \mathrm{~K}$, measured at $h \nu=910 \mathrm{eV}$. (f) Evolution of bulk and surface $\mathrm{Rh}$ species during post-annealing of $0.4 \mathrm{ML} \mathrm{Rh} / \mathrm{Pt}(111)$.

The oxidation of ammonia was studied at $600 \mathrm{~K}$, a temperature at which both $\mathrm{Pt}$ and $\mathrm{Rh}$ catalysts exhibit detectable activity. The sample temperature was controlled automatically and read out using a K-type thermocouple spotwelded onto the sample side.

Beamline. APXPS measurements were conducted at the HIPPIE beamline of the MAX IV Laboratory. The details of the beamline design can be found elsewhere. ${ }^{27}$ In brief, ambient pressure measurements were performed inside of an ambient pressure cell (Lund design ${ }^{28}$ ) at $1 \mathrm{mbar}$ with the sample surface heated to $600 \mathrm{~K}$ using a laser. Ambient pressure $\mathrm{X}$-ray photoelectron (APXP) spectra were recorded using a beamline monochromator exit slit of $60 \mu \mathrm{m}$, corresponding to a resolving power of around 7000 . The spectra were measured with the following parameters: $\mathrm{N} 1 \mathrm{~s}-600 \mathrm{eV}$ photon energy, $100 \mathrm{eV}$ pass energy, overall energy resolution $215 \mathrm{meV}$; O $1 \mathrm{~s}-830 \mathrm{eV}$ photon energy, $100 \mathrm{eV}$ pass energy, overall resolution $235 \mathrm{meV}$; Rh $3 \mathrm{~d}-910 / 610 \mathrm{eV}$ photon energy, 50 $\mathrm{eV}$ pass energy, overall resolution $165 / 135 \mathrm{meV}$; Pt 4d-910 or $610 \mathrm{eV}$ photon energy, $50 \mathrm{eV}$ pass energy, overall resolution $165 / 135 \mathrm{meV}$; and $\mathrm{Pt} 4 \mathrm{f}-675 \mathrm{eV}$ photon energy, $20 \mathrm{eV}$ pass energy, overall resolution $105 \mathrm{meV}$. More surface-sensitive measurements were performed at an electron kinetic energy of 200-300 eV and more bulk-sensitive measurements at 500$600 \mathrm{eV}$. The binding energies in all spectra are reported with accuracy $\pm 0.05 \mathrm{eV}$. They are referenced to the Fermi level, measured with the same photon energy, monochromator, and analyzer slits, and pass energy as the spectra themselves. Since at least five different $\mathrm{Rh}$ species may contribute to the narrow $\mathrm{Rh} 3 \mathrm{~d}$ region (307-308 eV binding energy), ${ }^{29}$ the binding energies of the $\mathrm{Rh} 3 \mathrm{~d}$ components are reported with two significant digits. During adjustment of the photon energy, the shutter to the X-ray beam was kept closed. For each gas exposure, APXP spectra were measured on a fresh spot of the sample. No quantifiable difference in the surface composition was detected between measurements at different spots.

XPS Data. XPS data were analyzed using the least-square curve-fitting software Winspec developed at the University of Namur, Belgium. ${ }^{30} \mathrm{Pt} 4 \mathrm{f}$ and $\mathrm{Rh} 3 \mathrm{~d}$ core levels were fitted with asymmetric peaks. The $\mathrm{N} 1 \mathrm{~s}$ and $\mathrm{O} 1 \mathrm{~s}$ spectra were fitted with Voigt functions. Shirley and linear backgrounds were used for baseline subtraction. The Pt $4 \mathrm{~d}_{5 / 2}$ peak measured on a clean $\mathrm{Pt}(111)$ surface was subtracted from some of the $\mathrm{Rh} 3 \mathrm{~d}$ spectra; the spectrum is included in Figure S1 for reference. All spectra were normalized to the number of scans. The coverage was calculated from intensities normalized to the subshell photoionization cross section at the used photon energies. ${ }^{31}$ No oxide formation was observed for the $\mathrm{Pt}(111)$ surface. This allowed us to use oxygen dosing at room temperature to prepare a $\mathrm{Pt}(111)$ surface with 0.25 monolayers (ML) of chemisorbed atomic $O$. This surface preparation then served as a reference for the estimation of nitrogen and oxygen coverages.

Gas Dosing. The APXPS experiments were carried out sequentially on each surface, all at a total pressure of $1 \mathrm{mbar}$ at $600 \mathrm{~K}$ : first in $\mathrm{O}_{2}$, followed by (99:1) and (50:50) mixtures of $\mathrm{O}_{2}+\mathrm{NH}_{3}$. A (99:1) mixture was achieved by dosing $0.5 \mathrm{mbar}$ of $\mathrm{O}_{2}$ (5.0, Linde) and 0.5 mbar diluted $\mathrm{NH}_{3}$ (0.005 mbar $\mathrm{NH}_{3}$ in 0.495 mbar of $\mathrm{Ar}$, mixed and calibrated at Nippon Gases). A (50:50) mixing was achieved by equal dosing of pure $\mathrm{O}_{2}$ and pure $\mathrm{NH}_{3}$ (5.0, Air Liquide). No additional tracers were used in the experiment. The control over the gas mixing was achieved via a baratron manometer and mass flow controllers. Using typical total gas flows of 8 normal mL/ min, the reactor residence time was estimated to be $7.5 \mathrm{~s}$.

Quadruple Mass Spectrometry. QMS was used to sample the gas composition. From the possible gas sampling locations at the cell inlet, outlet, and analyzer, ${ }^{32}$ the gas exiting the ambient pressure cell through the analyzer pumping line, closest to the sample reaction area, was used, allowing for the highest QMS sensitivity to the gas composition in the vicinity of the crystal studied with APXPS. ${ }^{32}$ Raw QMS (Hiden HAL/ 3F PIC) signals were used without calibration. Intensity of the reaction species $\left(\mathrm{NH}_{3}, \mathrm{~N}_{2}\right.$, and $\left.\mathrm{NO}\right)$ did not differ whether the shutter for X-rays was open or closed, confirming that the majority of the signal is not due to beam-assisted $\mathrm{NH}_{3}$ dehydrogenation. During dosing of pure $\mathrm{O}_{2}$, only a negligible background amount of $\mathrm{CO}$ was detected at $28 \mathrm{u}$. Therefore, during the oxidation reaction, the product at $28 \mathrm{u}$ was assigned to $\mathrm{N}_{2}$ and not to $\mathrm{CO}$.

Scanning Tunneling Microscopy. STM was performed in UHV using the ReactorSTM at the University of Oslo. 
a)

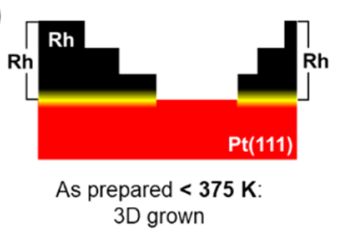

b)

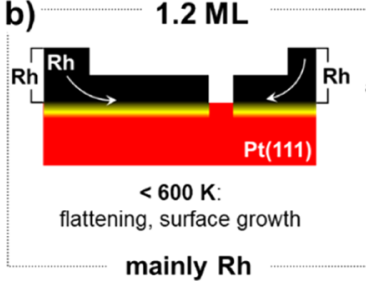

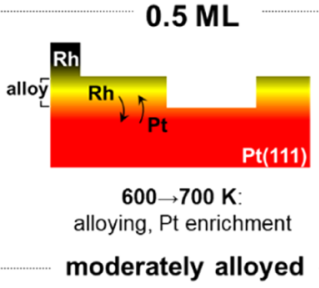

$0.4 \mathrm{ML}$

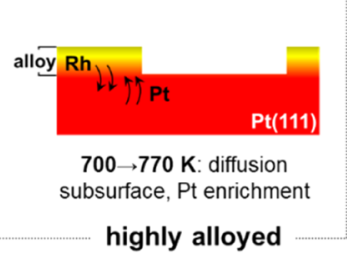

Figure 3. Cartoon drawing showing (a) multilayered, as-prepared $\mathrm{Rh} / \mathrm{Pt}(111)$ surface and (b) changes in the surface structure due to postannealing to below 600, to 700 , and to $770 \mathrm{~K}$ : flattening of the $\mathrm{Rh}$ islands, alloying resulting from $\mathrm{Pt}-\mathrm{Rh}$ interdiffusion, and $\mathrm{Rh}$ diffusion into $\mathrm{Pt}$ bulk above $700 \mathrm{~K}$.

Imaging was performed using cut PtIr tips at room temperature. To ensure the equivalence of the surfaces studied using STM and those prepared at the beamline, the coverage was cross-calibrated using previous combined STM and XPS results. ${ }^{25}$ The surfaces were analyzed after preparation at $375 \mathrm{~K}$ and after post-annealing to targeted temperature $600-770 \mathrm{~K}$. Images were processed using the WsXM software. ${ }^{33}$

\section{RESULTS AND INTERPRETATION}

Formation of a PtRh Surface Alloy. The oxidation of ammonia was investigated over a clean $\mathrm{Pt}(111)$ surface and three Rh-enriched $\mathrm{Pt}(111)$ surfaces prepared by deposition of $0.4,0.5$, and 1.2 ML of Rh. In this way, it was possible to study a number of different alloy compositions that cover the full range from a pure $\mathrm{Pt}$ surface via increasing $\mathrm{Rh}$ coverages to an almost fully Rh-covered surface. Basic characterization of the morphology of surface alloy surfaces was done by STM. The results of this characterization for the 0.5 and $1.2 \mathrm{ML}$ samples are reported in Figure $2 \mathrm{a}-\mathrm{d}$. The STM images of the $0.4 \mathrm{ML}$ preparation are very similar to those of the $0.5 \mathrm{ML}$ surface (not shown). The morphology of both preparations consists of three-dimensional pyramid-like islands of $\mathrm{Rh}$ on $\mathrm{Pt}(111)$. As we have reported previously, ${ }^{25}$ a substrate temperature below $375 \mathrm{~K}$ is not sufficient to overcome the interlayer diffusion barriers for $\mathrm{Rh}$ atoms to descend to a lower, incomplete $\mathrm{Rh}$ layer, and the deposition results in nucleation and growth of up to three incomplete layers even for a submonolayer coverage (Figure 2a).

Figure 2e displays the $\mathrm{Rh} 3 \mathrm{~d} \mathrm{XP}$ spectra of the $0.5 \mathrm{ML} \mathrm{Rh} /$ $\mathrm{Pt}(111)$ preparation. They are representative also of the spectra measured for the 0.4 and 1.2 ML $\mathrm{Rh} / \mathrm{Pt}(111)$ samples. The width of the peak for the as-prepared sample (upper spectra in Figure 2e) requires fitting with two components centered at 307.3 and $306.8 \mathrm{eV}$. The two components resemble $\mathrm{Rh}$ bulk (subsurface) and $\mathrm{Rh}$ surface species reported for $\mathrm{Rh}(111)$ but were found shifted ca. $+0.2 \mathrm{eV}$ with respect to 307.1 and $306.6 \mathrm{eV}$, respectively, commonly reported for $\mathrm{Rh}(111) .^{21,34,35}$ The shift to higher binding energy is tentatively assigned to the influence of the $\mathrm{Pt}(111)$ substrate. The spectrum was acquired with a bulk-sensitive photon energy of $910 \mathrm{eV}$, thus measuring the bulk component almost as intense as the surface component (cf. the summary in Figure 2f). This is in line with the morphology of the as-prepared samples observed by STM (Figure 2a,b), in which the second and third layers of Rh cover the lower Rh layers, creating a $\mathrm{Rh}$ "bulk" environment.

According to our roadmap for the preparation of PtRh surfaces, ${ }^{25}$ for a sample with $\mathrm{Rh}$ deposited onto $\mathrm{Pt}(111)$ at 375 $\mathrm{K}$, only a limited amount of mixing and interdiffusion occurs between the $\mathrm{Rh}$ overlayer and $\mathrm{Pt}(111)$ substrate. While $\mathrm{Pt}$ tends to dominate the surface of $\mathrm{Pt}_{25} \mathrm{Rh}_{75}$ bulk alloys in
$\mathrm{UHV},{ }^{11,36}$ a temperature above $600 \mathrm{~K}$ is needed to ensure $\mathrm{Pt}$ diffusion into the $\mathrm{Rh}$ islands, while a lower temperature results mainly in $\mathrm{Rh}$ island flattening. ${ }^{25}$ To establish a link between $\mathrm{Pt}-\mathrm{Rh}$ alloying and annealing temperature, the $0.4,0.5$, and 1.2 $\mathrm{ML} \mathrm{Rh} / \mathrm{Pt}(111)$ samples were post-annealed to $600-770$ $\mathrm{K}$ and imaged with STM (Figure 2c,d and corresponding XP spectrum in the bottom of Figure $2 \mathrm{e}$ ). As expected, a higher temperature enables the growth of large, faceted islands and more continuous $\mathrm{Rh}$ domains but some vacancy islands of bare $\mathrm{Pt}(111)$ remain as well. ${ }^{25}$ No significant difference is found in the morphology of the two surfaces with 0.4 and $0.5 \mathrm{ML} \mathrm{Rh}$ coverage, post-annealed to 770 and $700 \mathrm{~K}$, respectively (not shown).

To resolve the changes in $\mathrm{Rh}$ structure induced by annealing and thus conclude on alloying, we plot the evolution of the $\mathrm{Rh}$ surface and subsurface "bulk" components in the Rh $3 \mathrm{~d}$ spectra measured on the $0.4 \mathrm{ML}$ Rh sample during the post-annealing procedure (Figure 2f). Although the total apparent $\mathrm{Rh}$ coverage remains constant until $600 \mathrm{~K}$, the intensity of the bulk component drops almost fivefold, which corresponds to a decrease from 0.19 to $0.04 \mathrm{ML}$. The concomitant increase in surface component $(+0.16 \mathrm{ML})$ confirms the flattening of the layer, which is also observed in STM. Further post-annealing to $700 \mathrm{~K}$ results in the decrease of the overall coverage to $75 \%$ of the initial one. Eventually, upon annealing to $770 \mathrm{~K}$, only less than $50 \%$ of the initial $\mathrm{Rh}$ coverage remains within the layer probed by XPS. As a result, the final spectrum of the postannealed surface features only one main component (>90\%), related to Rh surface species. We can conclude from the $\mathrm{Rh} 3 \mathrm{~d}$ intensity that the coverage of $\mathrm{Rh}$ after post-annealing for the $0.40,0.50$, and $1.20 \mathrm{ML}$ surfaces becomes $0.18,0.36$, and 1.0 ML. As will be seen below, this coverage drop is reversible.

From the combined XPS and STM results, we conclude that post-annealing plays a key role in PtRh alloying (Figure 3). In particular, it was shown earlier that a temperature above $650 \mathrm{~K}$ favors $\mathrm{Pt}-\mathrm{Rh}$ interchange and $\mathrm{Pt}$ diffusion into $\mathrm{Rh}$ islands, which accounts for the apparent loss of $\mathrm{Rh}^{25}$ As a result, by controlling the post-annealing temperature, we are able to tune alloying within the surface from (a) minimum $\mathrm{Pt}$ enrichment (600 K, 1.2 ML Rh), (b) moderate Pt enrichment (700 K, 0.5 $\mathrm{ML} \mathrm{Rh}$ ), and (c) substantial PtRh alloying (770 K, 0.4 ML $\mathrm{Rh})$. The composition of the surface alloy sketched in Figure 3 depicts the likely mixing of the top bimetallic layer after postannealing and just before the operando studies. It is expected that the subsequent exposure to reaction mixtures will alter $\mathrm{Pt} /$ $\mathrm{Rh}$ proportion at the surface.

Oxidation of Rh Films on Pt(111). The basic structural characterization of the $\mathrm{PtRh}$ surfaces provides us with the necessary pre-knowledge to understand differences in oxidation behavior, which, in turn, will affect the ammonia oxidation behavior. Indeed, it will be seen that both the $\mathrm{Rh}$ 
a)

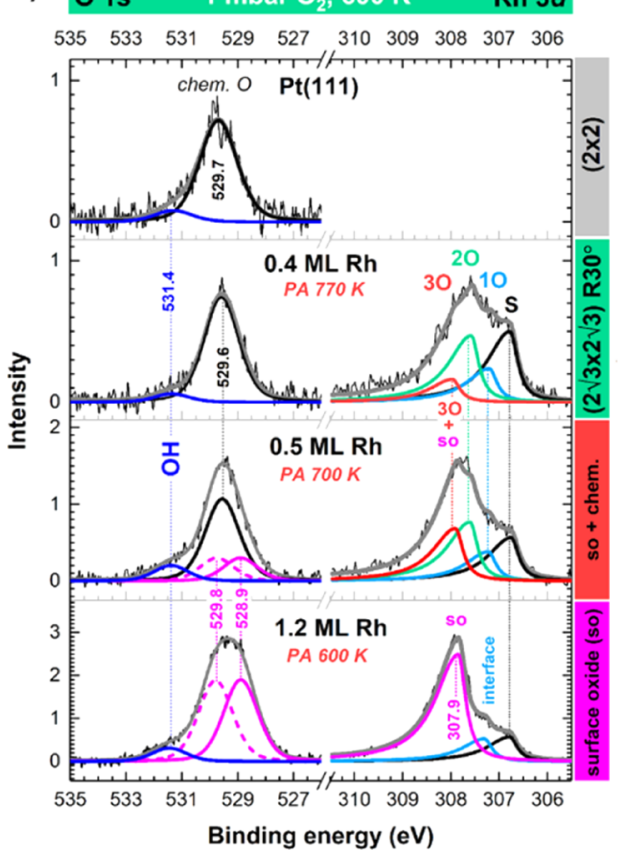

b)

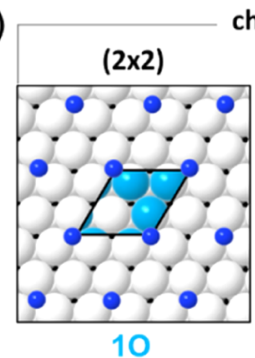

chemisorbed $\mathbf{O}$ structures

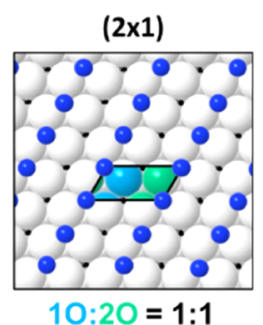

$10: 20=1: 1 \quad 10: 20: 30=3: 6: 3$

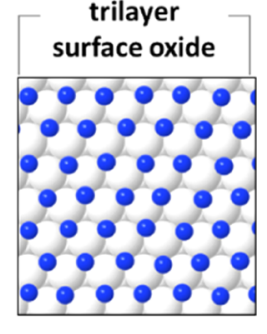

$1.2 M L R$

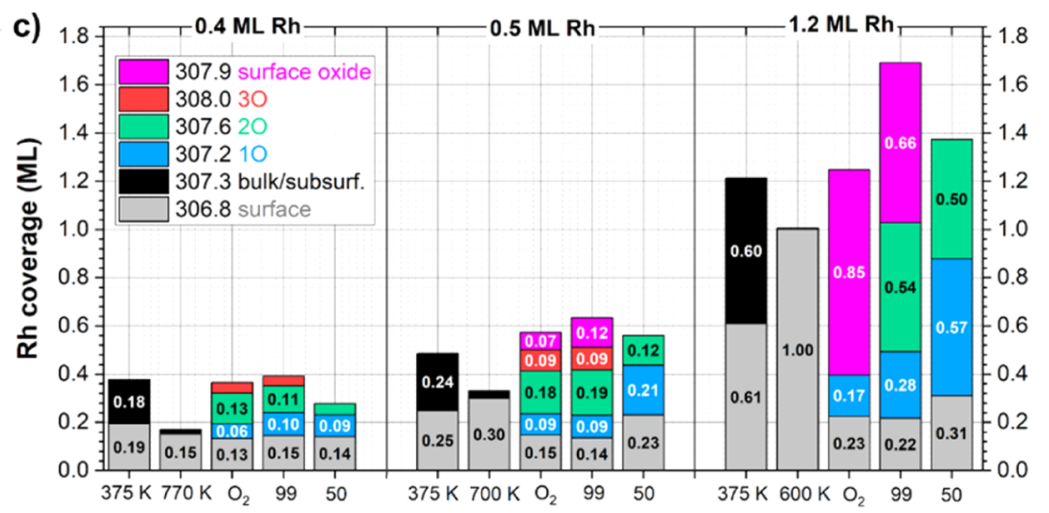

Figure 4. (a) O 1s and $\mathrm{Rh} 3 \mathrm{~d}$ APXP spectra of $\mathrm{Pt}(111)$ and $0.4-1.2 \mathrm{ML} \mathrm{Rh} / \mathrm{Pt}(111)$ in $1 \mathrm{mbar}$ of $\mathrm{O}_{2}$ at $600 \mathrm{~K}$, measured with $h \nu=1130$ and 910 $\mathrm{eV}$, respectively. (b) Oxygen structures possible on $\mathrm{Rh}(111)$ surface. (c) Evolution of the Rh coverage obtained from the curve-fitting of the Rh $3 \mathrm{~d}$ line for the 0.4-1.2 ML Rh/Pt(111) preparations: as prepared at $375 \mathrm{~K}$ (labeled $375 \mathrm{~K}$ ), post-annealed (labeled with post-annealing T, 600-770 $\mathrm{K})$, in $1 \mathrm{mbar} \mathrm{O}_{2}\left(\mathrm{O}_{2}\right)$, and in mixtures of $1 \mathrm{mbar}$ of $\mathrm{O}_{2}+\mathrm{NH}_{3}$ (99:1 and 50:50, labeled as 99 and 50, respectively), derived from fit shown in panel (a) and Figure 5 .

coverage and post-annealing temperature are important parameters for the result of the oxidation, and therefore, all $\mathrm{XP}$ spectra presented below are labeled with both, $\mathrm{Rh}$ coverage and post-annealing temperature.

Preceding ammonia oxidation, the $\mathrm{Pt}(111)$ and $\mathrm{Rh} / \mathrm{Pt}(111)$ samples with minimum (1.2 ML), moderate (0.5 ML), or substantial (0.4 ML) PtRh mixing were oxidized in 1 mbar of $\mathrm{O}_{2}$ at $600 \mathrm{~K}$. The $\mathrm{O} 1 \mathrm{~s}$ and $\mathrm{Rh} 3 \mathrm{~d}$ APXP spectra in Figure 4a allow us to compare the oxygen species on the $\mathrm{Pt}(111)$ surface and the $\mathrm{Rh}$ films on $\mathrm{Pt}(111)$. For $\mathrm{Pt}(111)$, the main component in the $\mathrm{O} 1 \mathrm{~s}$ region at $529.7 \mathrm{eV}$ is assigned to the $(2 \times 2)$ chemisorbed atomic oxygen layer (Figure $4 b),{ }^{37,38}$ and the absence of $\mathrm{Pt}$ oxide features in the $\mathrm{Pt} 4 \mathrm{f}$ spectrum confirms this assignment (Figure S2). The shoulder component at 531.4 $\mathrm{eV}$ is attributed to surface $-\mathrm{OH}$ groups formed from residual protons $^{21}$ and was found for samples exposed to all gas mixtures containing oxygen (see below).

Comparison of the $\mathrm{O} 1 \mathrm{~s}$ spectra of the $0.4 \mathrm{ML} \mathrm{Rh} / \mathrm{Pt}(111)$ and $\operatorname{Pt}(111)$ surfaces shows the same major component at $529.6 \mathrm{eV}$ (Figure 4a). The energy and absence of peak broadening suggest that oxygen on $\mathrm{Rh}$ islands and on bare $\mathrm{Pt}$ surrounding the islands is in a similar chemical environment, which is therefore related to chemisorbed oxygen. ${ }^{39}$ In contrast, for the higher-coverage 1.2 ML Rh film, we find a broader peak, which requires two components in the curve fit centered at 529.8 and $528.9 \mathrm{eV}$. The binding energy and separation $(0.85 \mathrm{eV})$ of these components are in line with the formation of a surface oxide trilayer $(\mathrm{O}-\mathrm{Rh}-\mathrm{O})$ composed of a metal (Rh) layer sandwiched between two oxygen layers (Figure $4 \mathrm{~b}){ }^{22}$ In the oxide trilayer, the lower-binding energy peak corresponds to the surface oxygen atoms and the higher one to subsurface oxygen atoms. We note that the equal intensity ratio of surface/subsurface oxygen components $(\sim 1.0)$ differs from 0.4 reported for the oxide grown on $\mathrm{Rh}(111),{ }^{22}$ that is, in our case, subsurface oxygen is less abundant. The lower amount of subsurface $\mathrm{O}$ can be rationalized by the presence of $\mathrm{Pt}(111)$ underneath $\mathrm{Rh}$, preventing the formation of a significant subsurface/interface O layer. The Rh trilayer oxide appears to exist also on the 0.5 $\mathrm{ML} \mathrm{Rh}$ sample, as is concluded from the existence of the shoulder at $528.9 \mathrm{eV}$. This component originates from the oxide surface. For this surface, the presence of two distinct types of oxygen domains suggests a mixed composition that consists of chemisorbed $-\mathrm{O}$ (main phase) and a small fraction (18\%) of the trilayer oxide.

The $\mathrm{Rh} 3 \mathrm{~d}$ core level of all samples is affected significantly by exposure to $1 \mathrm{mbar}$ of $\mathrm{O}_{2}$ at $600 \mathrm{~K}$ (Figure 4a). For the 0.4 ML Rh sample, three new components are identified at 307.25, 307.65 , and $307.90 \mathrm{eV}$ binding energy. The assignment of the components is based on literature data ${ }^{39}$ in combination with the following considerations: First, the photon-energy-dependent measurement (910 vs $610 \mathrm{eV}$ ) of the $\mathrm{Rh} 3 \mathrm{~d}$ level shows that the difference in probe depth does not affect the components' intensity ratios (not shown). This implies that all components relate to $\mathrm{Rh}$ species within the same (surface) layer as the surface species (labeled surface, S) at $306.80 \mathrm{eV}$. The first peak at $307.25 \mathrm{eV}$ is in the range where the components due to photoemission from the Rh bulk atoms and due to photoemission from the $\mathrm{Rh}$ atoms coordinated to one oxygen atom (1O) are expected. Since bulk Rh can be excluded based on the previous argument, we conclude that the component is due to $1 \mathrm{O} \mathrm{Rh}$ species. Second, the value of the binding energy of the component at $307.90 \mathrm{eV}$ would be in agreement with both $\mathrm{Rh}$ triply coordinated to oxygen (3O) and $\mathrm{Rh}$ in the trilayer surface oxide (labeled so). The latter possibility can, however, be excluded based on the absence of 

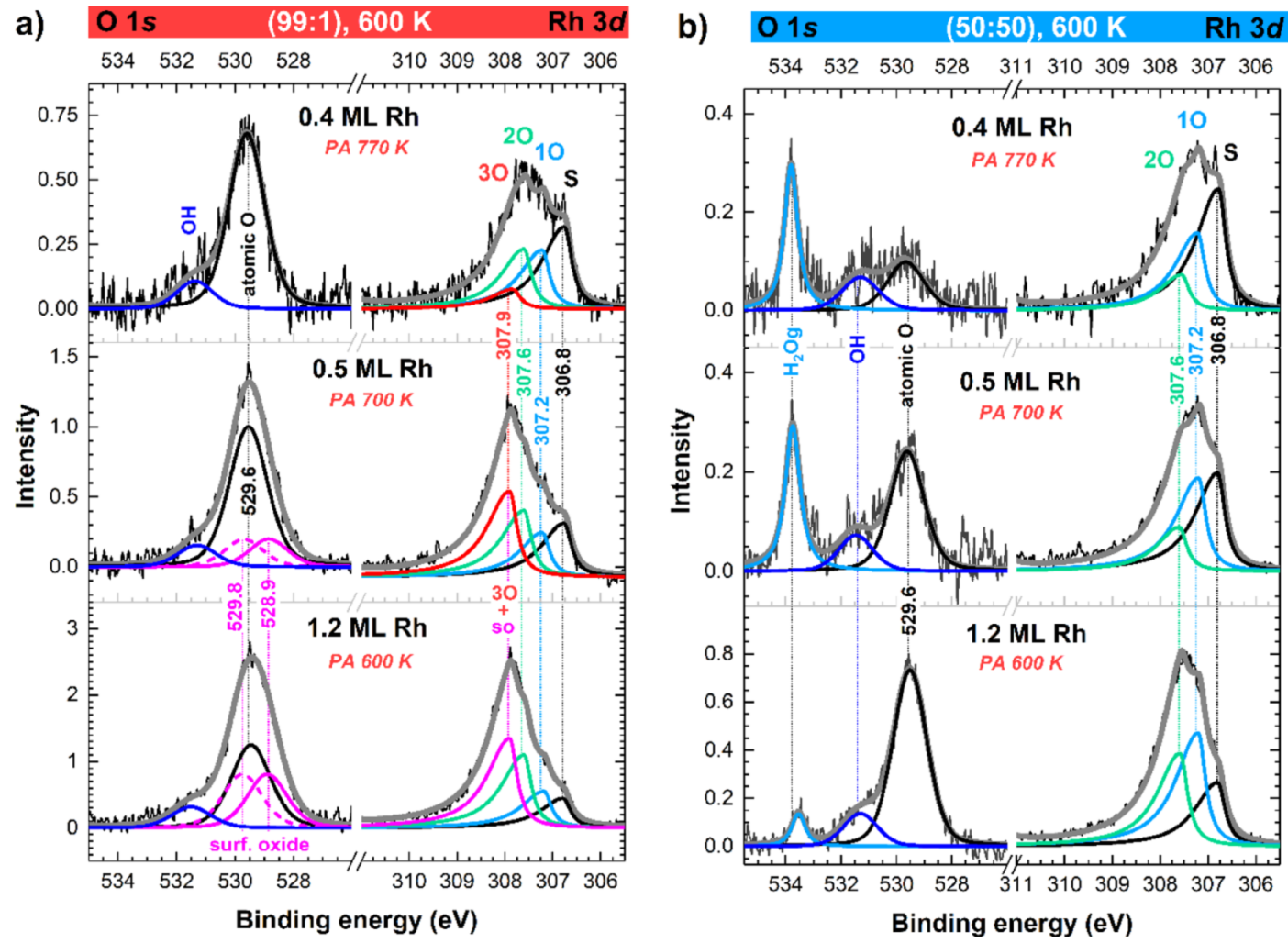

Figure 5. $\mathrm{O} 1 \mathrm{~s}$ and $\mathrm{Rh} 3 \mathrm{~d}$ APXP spectra of 0.4-1.2 $\mathrm{ML} \mathrm{Rh/Pt(111)} \mathrm{in} 1$ mbar of $\mathrm{O}_{2}+\mathrm{NH}_{3}$ mixed in (a) (99:1) and (b) (50:50) ratios at 600 K.

an oxide component at $528.9 \mathrm{eV}$ in the $\mathrm{O} 1 \mathrm{~s}$ spectrum of the $0.4 \mathrm{ML}$ sample. Hence, we assign this component to a $3 \mathrm{O} \mathrm{Rh}$ species. Third, as for the most intense component of the spectrum at $307.65 \mathrm{eV}$, in this binding energy range, the only possible contribution is from $\mathrm{Rh}$ doubly coordinated to oxygen ( $2 \mathrm{O}$ species, $+0.4 \mathrm{eV}$ from $\mathrm{Rh}$ bulk).

To identify the surface structure that results in the 10,20 , and $3 \mathrm{O}$ components in the $\mathrm{Rh} 3 \mathrm{~d}$ spectrum of the $0.4 \mathrm{ML} \mathrm{Rh} /$ $\mathrm{Pt}(111)$ preparation, we consider the possible oxygen phases with symmetry notations $(a)(2 \times 2)$, (b) $(2 \times 1)$, and (c) $(2 \sqrt{3} \times 2 \sqrt{3}) \mathrm{R}^{\circ} 0^{\circ}$ (Figure $\left.4 \mathrm{~b}\right)$. In these chemisorption structures, the Rh atoms are coordinated to (a) 10 only; (b) $1 \mathrm{O}$ and $2 \mathrm{O}$ ( $1: 1$ ratio); and (c) 1O, 2O, and $3 \mathrm{O}$ (3:6:3 ratio), respectively. The corresponding oxygen coverages are (a) 0.25 , (b) 0.5 , and (c) $0.67 \mathrm{ML}$. The observation of all three components in the spectrum with a $10 / 2 \mathrm{O} / 3 \mathrm{O}$ 1:2:0.7 intensity ratio (Figure $4 \mathrm{c}$ ) strongly suggests the presence of a $(2 \sqrt{ } 3 \times 2 \sqrt{ } 3) \mathrm{R} 30^{\circ}$ phase. The expected intensity ratio would be $1: 2: 1$, and the deviation of the observed intensity ratio from that expected implies defects in the $(2 \sqrt{3} \times 2 \sqrt{3}) \mathrm{R} 30^{\circ}$ structure and non-ideal $3 \mathrm{O}$ coordination. Significant coverage by a possible alternative structure of $(2 \times 2)-30,{ }^{39}$ which contains $3 \mathrm{O}$ coordination in proportion $0: 2.5: 1$ can be excluded based on the strong 10 and 20 components in the experimental data.

For the thicker $0.5 \mathrm{ML} \mathrm{Rh} / \mathrm{Pt}(111)$ layer, the presence of the surface oxide shoulder in the $\mathrm{O} 1 \mathrm{~s}$ core level suggests that the corresponding $\mathrm{Rh}$ species should give rise to a feature in the $\mathrm{Rh} 3 \mathrm{~d}$ spectrum with a binding energy of around 307.90$308.0 \mathrm{eV}$. Indeed, in comparison with the $\mathrm{Rh} 3 \mathrm{~d}$ spectra of the $0.4 \mathrm{ML}$ preparation, the intensity at $307.90 \mathrm{eV}$ is more than doubled (Figure 4c), and the peak ratio of 1:2:1.8 exceeds the 1:2:1 value expected for the $(2 \sqrt{ } 3 \times 2 \sqrt{ } 3) \mathrm{R} 30^{\circ}$ overlayer.
The Rh $3 \mathrm{O}$ excess peak intensity is estimated to be $1.8-1.0=$ 0.8 divided by the total $1+2+1.8=4.8$, that is, a fraction of ca. $+17 \%$. Despite a very rough estimation, this matches well with the magnitude of the shoulder in the $\mathrm{O} 1 \mathrm{~s}$ core level (18\%). As a result, ca. $18 \%$ of the $\mathrm{Rh}$, about $0.07 \mathrm{ML}$, is found to be present in the form of an oxide trilayer, while the rest, $0.38 \mathrm{ML}$, is present within the $(2 \sqrt{3} \times 2 \sqrt{3}) \mathrm{R}^{\circ} 0^{\circ}$ oxygen chemisorption structure.

With respect to the $1.2 \mathrm{ML} \mathrm{Rh} / \mathrm{Pt}(111)$ sample, the appearance of the $\mathrm{O}$ 1s line suggests that all oxygen belongs to the trilayer oxide. Hence, all $\mathrm{Rh}$ atoms coordinated to oxygen are also expected to be found within the trilayer oxide. Indeed, the expectation is in line with the shape of the $\mathrm{Rh} 3 \mathrm{~d}$ spectrum, which has a strongly dominating oxide component at 307.90 $\mathrm{eV}$ (Figure 4). In addition, there is a smaller component at $307.25 \mathrm{eV}$ binding energy. We attribute this component to the interface $\mathrm{Rh}$ atoms that reside between the trilayer oxide and the bulk metal. The assignment is in agreement with what is found when a bulk $\mathrm{Rh}(111)$ crystal is oxidized. In that case, the interface component has significant intensity and binding energy that is lower than that of the $\mathrm{Rh}$ bulk metal component by $0.25 \mathrm{eV}$. In the present case, the energy is somewhat higher, which can possibly be attributed to alloying or interfacing with bulk Pt.

To evaluate the coverage of chemisorbed oxygen and oxide quantitatively, we compare the $\mathrm{O}$ 1s peak intensity of spectra taken on the $\mathrm{Rh} / \mathrm{Pt}(111)$ surfaces with that measured on the $\mathrm{Pt}(111)$ surface, for which atomic $-\mathrm{O}$ saturates at a coverage of $0.25 \mathrm{ML}$. From this comparison, the $-\mathrm{O}$ coverages can be determined as $0.27,0.38$, and $1.30 \mathrm{ML}$ for the $0.4,0.5$, and 1.2 $\mathrm{ML} \mathrm{Rh/Pt(111)} \mathrm{surfaces,} \mathrm{respectively.} \mathrm{In} \mathrm{particular,} \mathrm{the}$ oxygen coverage for the 1.2 ML $\mathrm{Rh} / \mathrm{Pt}(111)$ exceeds $1 \mathrm{ML}$ : clearly, more than one oxygen layers are present, and they are 

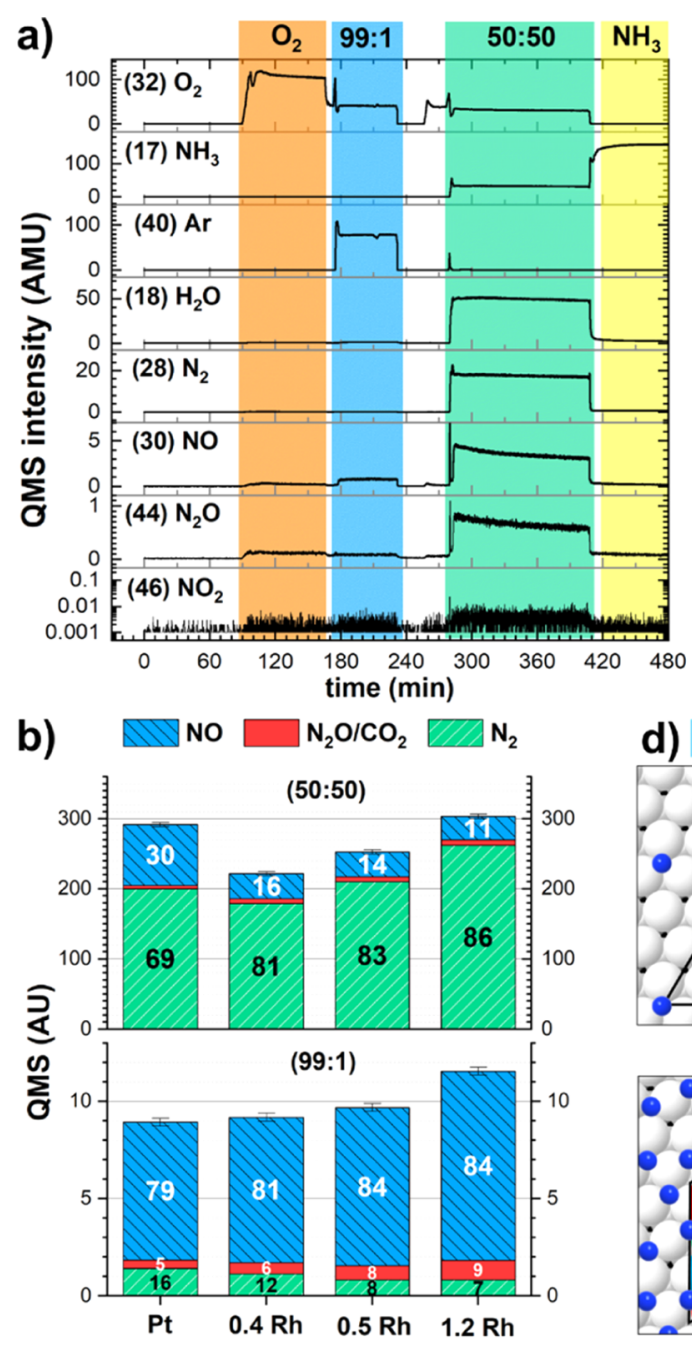

d)
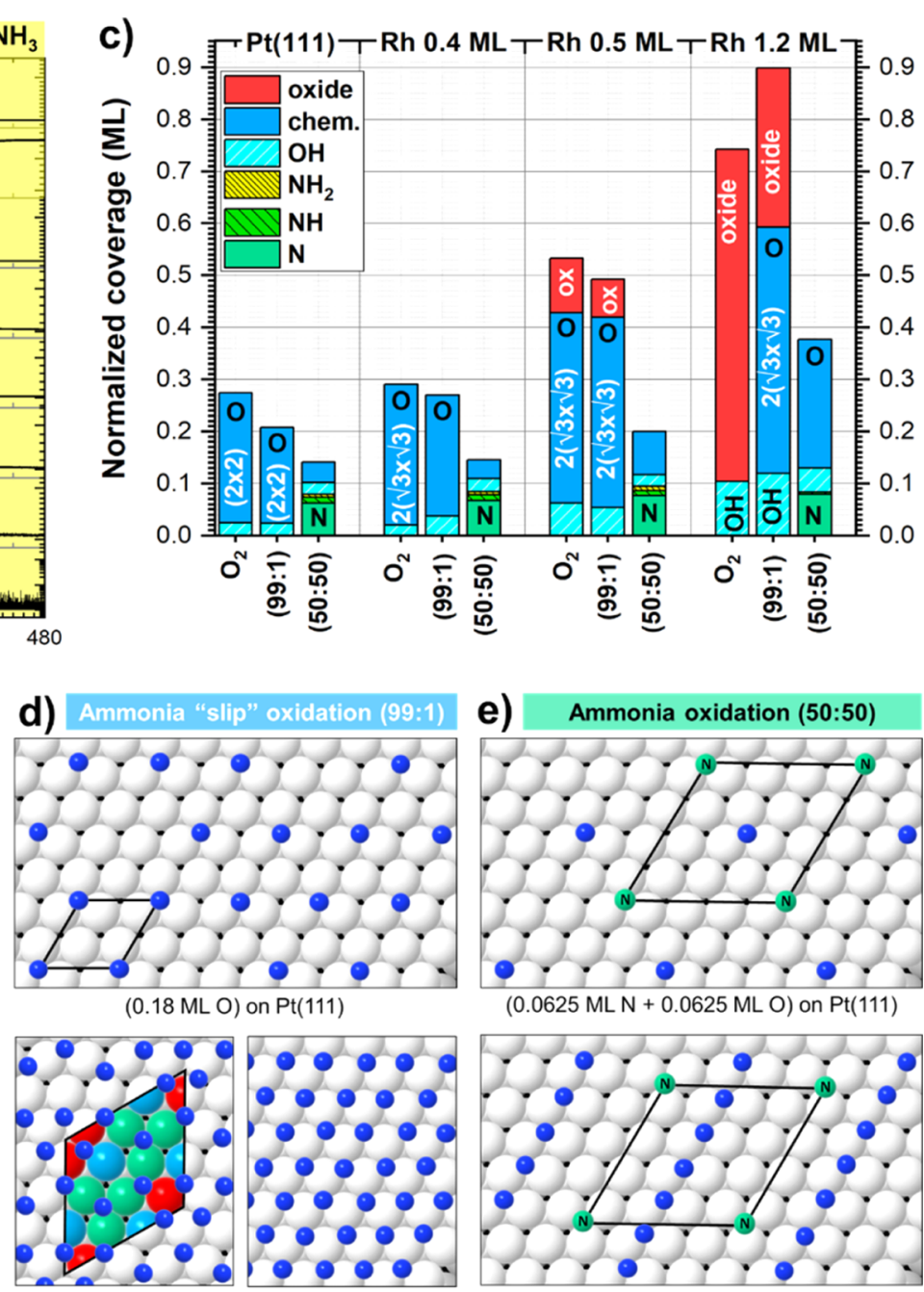

$(0.23 \div 0.5 \mathrm{ML} \mathrm{O}+\leq 0.3 \mathrm{ML}$ oxide $)$ on $\mathrm{Rh} / \mathrm{Pt}(111)$
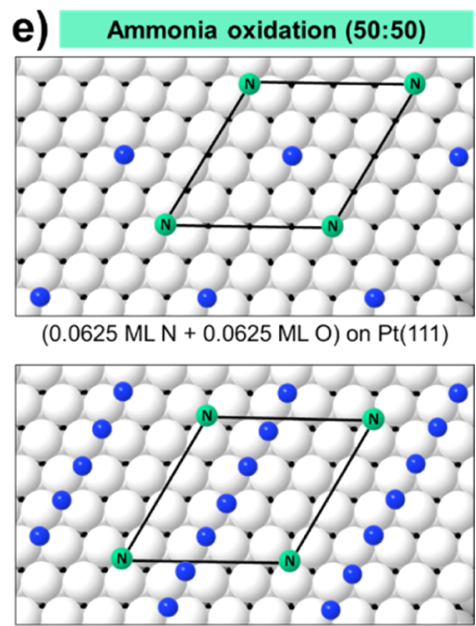

$(0.0625 \mathrm{MLN}+0.25 \mathrm{ML} \mathrm{O})$ on $\mathrm{Rh}(111)$

Figure 6. (a) QMS data taken during the exposure of $0.4 \mathrm{ML} \mathrm{Rh} / \mathrm{Pt}(111)$ sample to 1 mbar containing $\mathrm{O}_{2}, \mathrm{O}_{2}+\mathrm{NH}_{3}$ (99:1 and 50:50 mixtures), and pure $\mathrm{NH}_{3}$ at $600 \mathrm{~K}$. Monitored masses are indicated in brackets. (b) Product distribution based on QMS data for the Pt(111) and 0.4-1.2 ML $\mathrm{Rh} / \mathrm{Pt}(111)$ samples. Numbers in the bar chart represent \% of a given N-based product in the total QMS signal of N-species. (c) Surface coverage of $\mathrm{O}$ - and $\mathrm{N}$-based species observed in $\mathrm{O} 1 \mathrm{~s}$ and $\mathrm{N} 1 \mathrm{~s}$ spectra during dosing at $1 \mathrm{mbar}$ at $600 \mathrm{~K}$. The main oxygen structures are indicated in parentheses and are concluded upon from the $\mathrm{Rh} 3 \mathrm{~d}$ curve fit. Submonolayer $\mathrm{Rh}$ samples also feature domains of $(2 \times 2)$-O-covered $\mathrm{Pt}(111)$. To allow a proper comparison of coverages, for the trilayer oxide, only the surface oxygen is included in the graph, while in reality, subsurface oxygen nearly doubles the $\mathrm{O}$ coverage. $(\mathrm{d}, \mathrm{e})$ Schematic drawing of approximate $\mathrm{O}$ - and $\mathrm{N}$-structures on the $\mathrm{Pt}(111)$ and $\mathrm{Rh} / \mathrm{Pt}(111)$ surfaces during $\mathrm{NH}_{3}$ "slip" oxidation and $\mathrm{NH}_{3}$ oxidation. The sketches are based on data from panel (c). $-\mathrm{O}$ and $-\mathrm{N}$ are displayed as blue and green spheres respectively.

attributed to the surface and subsurface species in the trilayer oxide. In addition, the intensities of the $\mathrm{Rh} 3 \mathrm{~d}$ components allow for parallel estimation of the number of oxygen atoms that are bonded to $\mathrm{Rh}$ only: for the $0.4 \mathrm{ML} \mathrm{Rh} / \mathrm{Pt}(111)$ surface, $0.15 \mathrm{ML} \mathrm{Rh}-\mathrm{O}$ are found, that is, $38 \%$ of the $\mathrm{Rh}$ atoms are bonded to $-\mathrm{O}$ ); for the $0.5 \mathrm{ML} \mathrm{Rh} / \mathrm{Pt}(111)$, the corresponding numbers are $0.23 \mathrm{ML}$ of chemisorbed oxygen and $0.09 \mathrm{ML}$ of the trilayer oxide, and thus $46+18 \%=64 \%$ of the $\mathrm{Rh}$ atoms are bonded to oxygen; and for the $1.2 \mathrm{ML} \mathrm{Rh} /$ $\mathrm{Pt}$ (111) $0.85 \mathrm{ML}$ are found oxidized, that is, $85 \%$ of the $\mathrm{Rh}$ atoms are bonded to oxygen. Thus, all $\mathrm{Rh}$-containing alloys exhibit $-\mathrm{O}$ coverages that significantly exceed the oxygen coverages expected for a bare $\mathrm{Pt}(111)$ surface.

From the clearly visible $\mathrm{Rh}$ surface component at $306.8 \mathrm{eV}$ in the $\mathrm{Rh} 3 \mathrm{~d}$ spectra during oxidation, it becomes apparent that a portion of the surface $\mathrm{Rh}$ atoms (cf. the $\mathrm{S}$ surface component in Figure 4, which amounts to a fraction of $0.13-0.23 \mathrm{ML}$ of the $\mathrm{Rh}$ atoms) remains not coordinated to oxygen. This is rather notable. The oxygen pressures employed in the experiments are relatively high and would normally result in the formation of a surface oxide as observed for the $\mathrm{Rh}(111)$ surface. ${ }^{39}$ One plausible explanation for surface Rh to maintain no coordination to oxygen relies on the formation of disordered surface defects during the formation of the PtRh alloy. Since the amount of surface $\mathrm{Rh}$ not coordinated to oxygen was consistent throughout further exposure to $\mathrm{O}_{2}$ and $\mathrm{NH}_{3}$ mixtures (Figure $4 \mathrm{c}$ ), these species were considered as spectators.

Surface Composition in 1 mbar of $\mathrm{O}_{2}+\mathrm{NH}_{3} \cdot \mathrm{NH}_{3}$ "slip" oxidation was conducted in a gas mixture with large oxygen excess $\left(\mathrm{O}_{2} / \mathrm{NH}_{3}=99: 1\right)$ at $1 \mathrm{mbar}$ total pressure and partial pressures of $0.5 \mathrm{mbar}_{2}, 0.005 \mathrm{mbar} \mathrm{NH}_{3}$, and 0.495 mbar Ar. In comparison to the oxidation experiments reported above, the environment has a reduced oxygen pressure and $\mathrm{Ar}$ 

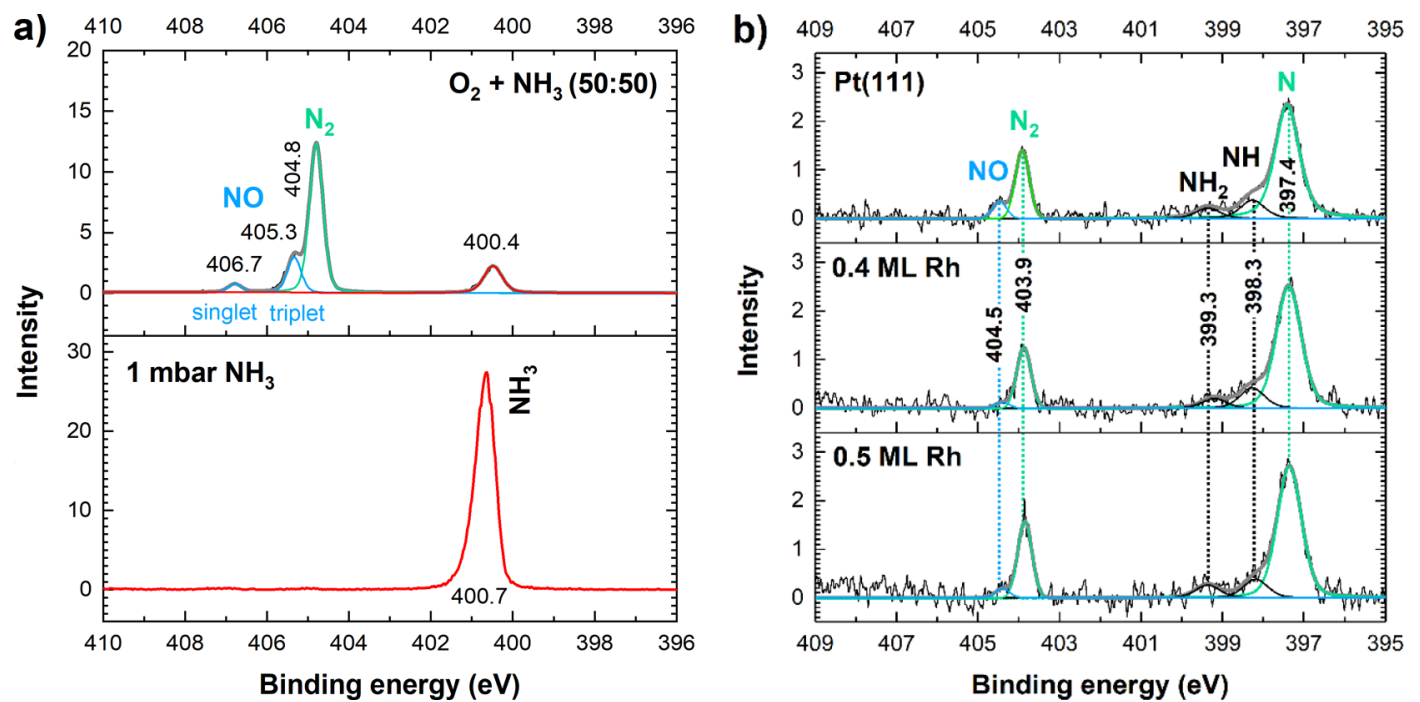

Figure 7. (a) Gas-phase APXP spectra measured at 1 mbar containing $\mathrm{O}_{2}+\mathrm{NH}_{3}$ (50:50) (top panel) and pure $\mathrm{NH}_{3}$ (bottom panel) over Pt(111) at $600 \mathrm{~K}$. (b) APXP spectra of the $\mathrm{N} 1 \mathrm{~s}$ core level of the $\mathrm{Pt}(111)$ and $0.4-0.5 \mathrm{ML} \mathrm{Rh} / \mathrm{Pt}(111)$ samples during exposure to $1 \mathrm{mbar}_{2}+\mathrm{NH}_{3}$ (50:50) at $600 \mathrm{~K}$. In (b), the gas-phase $\mathrm{N}_{2}$ and NO signals are found at 403.9 and $404.5 \mathrm{eV}$ binding energy, respectively (only the triplet component of gas-phase NO is detected). All spectra collected with $E_{\mathrm{ph}}=600 \mathrm{eV}$.

carrier gas. The reduction in oxygen pressure and the presence of $1 \% \mathrm{NH}_{3}$ bring about noticeable changes in the $\mathrm{O} 1 \mathrm{~s}$ and $\mathrm{Rh}$ 3d APXP spectra (Figure 5a). For the 1.2 ML Rh/Pt(111) sample, the component that corresponds to the surface oxide is reduced to approximately half its original intensity in both $\mathrm{O}$ $1 \mathrm{~s}$ and $\mathrm{Rh} 3 \mathrm{~d}$ core-level spectra. Instead, a component related to chemisorbed $2 \mathrm{O}$ species emerges, which confirms a partial reduction of the surface oxide and coexistence of the remaining surface oxide with chemisorbed $\mathrm{O}$ domains. Overall, the comparison of the surface composition in pure $\mathrm{O}_{2}$ and in mixture with $1 \% \mathrm{NH}_{3}$ shows that in both environments $\mathrm{Rh}$ remains highly coordinated to $\mathrm{O}$ (see quantification in Figure $4 c)$ and forms coexisting domains of the surface oxide (0.66 $\mathrm{ML}$ in $1.2 \mathrm{ML} \mathrm{Rh})$ and $(2 \sqrt{3} \times 2 \sqrt{3}) \mathrm{R} 30^{\circ}$ structure.

However, a $100 \times$ increase in partial pressure of $\mathrm{NH}_{3}$ to 0.5 mbar, that is, the transition to a (50:50) $\mathrm{O}_{2} / \mathrm{NH}_{3}$ mixture, results in more drastic changes of the surface composition (Figure 5b). For all $\mathrm{Rh}$ films, the intensity of the peak in $\mathrm{O} 1 \mathrm{~s}$ core level decreases substantially. The absence of the component at $528.9 \mathrm{eV}$ for the 0.5 and $1.2 \mathrm{ML}$ samples indicates that the oxide trilayer has vanished from the surface, and the remaining main component at $529.6 \mathrm{eV}$ thus represents chemisorbed oxygen. Spectroscopic evidence of a reaction between $\mathrm{O}_{2}$ and $\mathrm{NH}_{3}$ is found from the new peak at $533.9 \mathrm{eV}$ that originates from gas-phase ${ }^{40} \mathrm{H}_{2} \mathrm{O}$ (the gas-phase $\mathrm{H}_{2} \mathrm{O}$ peak can be unambiguously identified ${ }^{41}$ from its separation from the $\mathrm{O} 1 \mathrm{~s}$ gas-phase peak in Figure S3). No surface-bound $-\mathrm{H}_{2} \mathrm{O}$, which is expected to have an $\mathrm{O} 1 \mathrm{~s}$ component at 532.5-533.5 eV binding energy, ${ }^{42}$ is observed. These findings are in line with the $600 \mathrm{~K}$ reaction mechanism proposed in refs 15 and 16, according to which water surface species are not present due to fast desorption, ${ }^{10}$ thus resulting in low $\mathrm{H}_{2} \mathrm{O}$ surface coverage under the reaction conditions. ${ }^{43}$ As was mentioned earlier, surface $-\mathrm{OH}$ groups were observed in all cases. ${ }^{21}$

Another species forming during $\mathrm{NH}_{3}$ oxidation is $\mathrm{NO}$. When adsorbed at the surface, its $\mathrm{O}$ 1s component is expected at $530.8 \mathrm{eV}$ binding energy (see also Figures S4 and S5). ${ }^{44,45}$ Such a component is not detected. This is in agreement with the literature reporting desorption of $\mathrm{NO}$ from the $\mathrm{Pt}(410)$ surface at a temperature between 430 and $530 \mathrm{~K}^{8}$ The desorbed NO is expected to produce a gas-phase peak at around $538 \mathrm{eV}^{46}$ however, it is not possible to distinguish any such well-defined peak due to the overlap with the oxygen gasphase doublet at 537-538 eV binding energy (see Figure S3).

The absence of an oxide component in the $\mathrm{O} 1 \mathrm{~s}$ region matches the observations in the $\mathrm{Rh} 3 \mathrm{~d}$ core level spectrum (Figure $5 \mathrm{~b}$ ). For all $\mathrm{Rh}$ films, the signals due to the $\mathrm{Rh}$ oxide and $3 \mathrm{O}$ species are no longer present. The ratio of the remaining $1 \mathrm{O}$ and $2 \mathrm{O}$ contributions is close to $1.8: 1$ for the 0.4-0.5 ML and 1.1:1 for the 1.2 ML preparation (see Figure $4 \mathrm{c}$ for quantification). The latter ratio matches well with the $1: 1$ value expected for the $(2 \times 1)$ surface structure (Figure $4 \mathrm{~b})$. For the lower $\mathrm{Rh}$ coverage samples, an excess in the $1 \mathrm{O}$ component hints at a structure with single-oxygen coordination only, that is, a $(2 \times 2)$ surface structure, which coexists (ca. $15 \%)$ with the $(2 \times 1)$ main phase. Although the $2 \mathrm{O}$ components in the $\mathrm{Rh} 3 \mathrm{~d}$ spectra strongly suggest the presence of a $(2 \times 1)$ surface structure with $\mathrm{O}$ coverage of $0.5 \mathrm{ML}$, the observed coverage was substantially lower (0.1-0.25 ML). Therefore, the assignment of surface structures will be revised below, and in this new assignment, the nitrogen coverage will be taken into account, as well.

Analysis of the Gas-Phase Reaction Products. To help with the assignment of the species found in the $\mathrm{N} 1 \mathrm{~s}$ region, QMS data for the reaction over the $0.4 \mathrm{ML} \mathrm{Rh} / \mathrm{Pt}(111)$ sample were analyzed (Figure 6a). For the (99:1) gas mixture, QMS shows the expected products $\mathrm{N}_{2}, \mathrm{NO}, \mathrm{N}_{2} \mathrm{O}$, and $\mathrm{H}_{2} \mathrm{O}$, except $\mathrm{NO}_{2}$, which was at the detection limit of QMS (Figure $S 7$ shows this region in better detail). The relative contribution of all N-based species, plotted at the bottom of Figure $6 \mathrm{~b}$, shows that $\mathrm{NO}$ is the main oxidation product for all surfaces. Its signal accounts for $79-84 \%$ of all $\mathrm{N}$-based products, followed by $\mathrm{N}_{2}$ at around $7-16 \%$ and $\mathrm{N}_{2} \mathrm{O}$ at 5-9\%. The latter signal (44) could be also attributed to $\mathrm{CO}_{2}$, which was also observed during the dosing of pure $\mathrm{O}_{2}$, and therefore, the estimation of $\mathrm{N}_{2} \mathrm{O}$ contribution has a significant error bar (Figure S7). Furthermore, a comparison of the product 
distribution for the bare $\mathrm{Pt}(111)$ and 0.4-1.2 ML Rh/Pt(111) samples indicates that $\mathrm{Rh}$ enrichment results in a lower fractional production of $\mathrm{N}_{2}$ (decrease from 16 to $7 \%$ ) and in a somewhat larger fraction of NO (increase from 79 to $84 \%$ ).

An increase in partial pressure of $\mathrm{NH}_{3}$ to $0.5 \mathrm{mbar}$ (see 50:50 region in Figure 6a) while keeping the $\mathrm{O}_{2}$ pressure at 0.5 mbar results in significantly stronger (ca. $25 \times$ ) signals of the oxidation products $\mathrm{N}_{2}, \mathrm{NO}, \mathrm{N}_{2} \mathrm{O}$, and $\mathrm{H}_{2} \mathrm{O}$. The product distribution plotted in Figure $6 \mathrm{~b}$ (top) shows that $\mathrm{N}_{2}$ is the main product $(69-86 \%)$ for all surfaces, with significant amounts of $\mathrm{NO}(11-30 \%)$ and minor production of $\mathrm{N}_{2} \mathrm{O}(2-$ $3 \%)$. In contrast to the excess oxygen conditions (99:1), where the enrichment with $\mathrm{Rh}$ results in lower production of $\mathrm{N}_{2}$, in the (50:50) gas mixture, Rh surfaces yield a higher fractional production of $\mathrm{N}_{2}$ and a corresponding decrease in the production of $\mathrm{NO}$ and $\mathrm{N}_{2} \mathrm{O}$.

Despite pronounced changes in product distribution, it is notable in QMS presented in Figure $6 \mathrm{~b}$ that the total production of $\mathrm{N}$-based species is not strikingly different for $\operatorname{Pt}(111)$ and for Rh-enriched surfaces, being, respectively, about 250 and $10 \mathrm{AU}$ for (50:50) and (99:1) mixing. This observation of the apparent comparable activity of $\mathrm{Pt}(111)$ and $\mathrm{Rh} / \mathrm{Pt}(111)$ is in line with the N 1s APXPS results presented below but cannot be used as evidence of similar catalytic activity due to the design of the operando cells for APXPS. However, we would like to emphasize that a realistic estimation of the catalytic activity requires a dedicated kinetic experiment and is expected to show large differences in activity between pure $\mathrm{Pt}, \mathrm{Rh}$, and their alloys. ${ }^{47,48}$

Formation of Surface $\mathbf{N}$ Species. A typical gas-phase $\mathrm{N}$ 1s APXP spectrum of $\mathrm{O}_{2}+\mathrm{NH}_{3}$ (50:50) collected with the sample retracted from the analyzer focus is presented in Figure $7 \mathrm{a}$, top. It contains three peaks at 400.4, 404.8, and $406.7 \mathrm{eV}$. Based on the QMS results (Figure 6a), the nitrogen-based $\mathrm{NH}_{3}, \mathrm{~N}_{2}$, and $\mathrm{NO}$ signals are expected. The peak at $400.4 \mathrm{eV}$ belongs to gas-phase $\mathrm{NH}_{3}$ and is the only peak found while dosing pure $\mathrm{NH}_{3}$ (Figure 7a, bottom). The main peak at 404.8 $\mathrm{eV}$ in the spectrum is attributed to $\mathrm{N}_{2}{ }^{49}$ On the higher binding energy side, it has a shoulder at $405.3 \mathrm{eV}$ plus a small peak at $406.8 \mathrm{eV}$, that is, $1.45 \mathrm{eV}$ higher in energy than the shoulder. These two signals arise from the triplet and singlet components of NO, which are separated by $1.50 \mathrm{eV}$ according to the literature. ${ }^{50}$ Overall, the gas-phase intensities for $\mathrm{N}(75 \%)$ and NO (25\%) observed in the N 1s spectrum are in reasonable agreement with the QMS data.

Based on QMS and gas-phase APXPS, one could expect to find $-\mathrm{N}$ and $-\mathrm{NO}$ as surface-adsorbed species during the $\mathrm{O}_{2} /$ $\mathrm{NH}_{3}$ (50:50) exposure. Indeed, in the $\mathrm{N} 1$ s core level spectrum of $\mathrm{Pt}(111)$, the major peak corresponding to atomic $\mathrm{N}$ is found at $397.4 \mathrm{eV}$ (Figure 7b). Although an $\mathrm{NH}_{3}$ peak at 399.8$400.0 \mathrm{eV}$ is not observed (see the spectrum during pure $\mathrm{NH}_{3}$ dosing in Figure S6), the intermediate products of ammonia dehydrogenation $\mathrm{NH}_{x}$ produce a shoulder at around 398.3$399.3 \mathrm{eV}$. The absence of a distinct $\mathrm{NH}_{3}$ peak in the spectra of all samples points at the complete conversion of all $\mathrm{NH}_{3}$ available near the surface for all studied compositions. This indicates that the reaction rate is faster than the supply of fresh $\mathrm{NH}_{3}$. Another strong peak, located at $403.9 \mathrm{eV}$, is attributed to gas-phase $\mathrm{N}_{2}{ }^{49}$ Furthermore, NO peaks expected at 400.4$401.3 \mathrm{eV}^{51-53}$ are not detected, in agreement with the absence of an NO component in the $\mathrm{O} 1 \mathrm{~s}$ core level spectrum (Figures $\mathrm{S} 4$ and S5). Indeed, the absence of surface NO peaks is justified by rapid NO desorption, which is faster than its formation or decomposition to $\mathrm{N}$ and $\mathrm{O}$ on Pt surfaces. ${ }^{8,19}$

According to QMS, a significant production of NO [30\% for $\mathrm{Pt}(111)]$ and fast NO desorption from the surface is expected to result in observable gas-phase peak. Indeed, for $\mathrm{Pt}(111)$ a high-binding energy shoulder is found at $404.5 \mathrm{eV}$ (Figure $7 \mathrm{~b}$, middle), which is attributed to the gas-phase NO (triplet) species. ${ }^{51}$ For $0.4-1.2 \mathrm{ML} \mathrm{Rh} / \mathrm{Pt}(111)$, production of $\mathrm{NO}$ is 2-3 times lower (according to the QMS data in Figure 6b), which results in a lower peak intensity.

Adsorbate Coverage during $\mathrm{NH}_{3}$ Oxidation. Figure $6 \mathrm{c}$ compares the surface coverages of the $\mathrm{O}$ - and $\mathrm{N}$-based species found in the APXP spectra for the $\mathrm{Pt}(111)$ and 0.4-1.2 ML $\mathrm{Rh} / \mathrm{Pt}(111)$ samples in pure $\mathrm{O}_{2}$ and $\mathrm{O}_{2}+\mathrm{NH}_{3}$ mixtures (Figures 4, 5, and 7). The gradual Rh-enrichment produces a few general trends in the coverage evolution. (a) In $\mathrm{O}_{2}$, the enrichment of $\mathrm{Pt}(111)$ with $\mathrm{Rh}$ leads to higher metal-oxygen coordination $(\mathrm{Rh}-2 \mathrm{O}, \mathrm{Rh}-3 \mathrm{O})$, which allows for overall larger oxygen coverage. (b) Similarly, the coverage of hydroxy groups $-\mathrm{OH}$ also scales with the enrichment in $\mathrm{Rh}$. Furthermore, the $-\mathrm{OH}$ presence is affected by the proportion of $\mathrm{O}_{2}$ in the feed. A large number of surface hydroxy groups are found in oxygen-rich mixtures (pure $\mathrm{O}_{2}$ and 99:1), but in (50:50) mixture, the number is roughly halved. (c) In contrast to the $-\mathrm{O}$ coverage, the coverage of surface-bound atomic nitrogen is independent of surface composition. Surface $-\mathrm{N}$ is reliably detected in the (50:50) mixture, at a coverage of 0.07 $\pm 0.01 \mathrm{ML}$.

The presence of a small fraction of $\mathrm{NH}_{3}$ in the (99:1) gas mixture is unable to change the surface structures formed in prior dosing of pure $\mathrm{O}_{2}$. Consequently, the same surfaces structures are observed as for pure $\mathrm{O}_{2}$, albeit with smaller coverage (Figure $6 \mathrm{~d})$ : the $(2 \times 2)$-O structure on $\mathrm{Pt}(111)$ and a combination of $(2 \sqrt{3} \times 2 \sqrt{3})$ R $30^{\circ}$ and surface oxide structures on $\mathrm{Rh} / \mathrm{Pt}(111)$. Essentially, during the reaction in excess oxygen, the surface is predominantly covered by $\mathrm{O}$ based species: $-\mathrm{OH}(0.02-0.12 \mathrm{ML})$, chemisorbed oxygen (0.2-0.5 ML), and oxide (0.1-0.3 ML).

During the dosing of a (50:50) gas mixture, a substantial portion of surface oxygen is consumed and about $0.07 \pm 0.01$ $\mathrm{ML}$ of $\mathrm{N}$ is added to the surface structure. Based on the observations, we can tentatively suggest models for the predominant surface structures, and to do so, we consider $\mathrm{Pt}(111)$ and $\mathrm{Rh} / \mathrm{Pt}(111)$ separately. Starting with the $\mathrm{Pt}(111)$ surface, $0.07 \mathrm{ML} \mathrm{N}$ is fairly close to $0.0625 \mathrm{ML}$, which is 4 times fewer than in a $(2 \times 2)-\mathrm{N}$ superstructure at $0.25 \mathrm{ML}$ coverage (Figure 6e). Therefore, $0.0625 \mathrm{ML} \mathrm{N}$ can be accommodated in a proportionally $(2 \times)$ larger adsorbate (4 $\times 4)$ - $\mathrm{N}$ superlattice. The oxygen coverage is $0.04 \mathrm{ML}$, which is somewhat lower than the $0.0625 \mathrm{ML}$ that would correspond to a perfect $(4 \times 4)$ superstructure. Hence, a portion of the $(4 \times$ 4)-N cells will feature $\mathrm{O}$ in their center and others will not, and the average surface overlayer can be depicted as a $(4 \times 4)-1 \mathrm{~N}-$ $0.57 \mathrm{O}$ structure. The suggested surface overlayer is shown in Figure 6e. For the Rh-terminated surface of the 1.2 ML Rh/ $\mathrm{Pt}$ (111) sample, the APXPS results provide two important observations: (1) the chemisorbed $-\mathrm{O}$ coverage is $0.25 \mathrm{ML}$ and (2) $\mathrm{Rh}-1 \mathrm{O}$ and $\mathrm{Rh}-2 \mathrm{O}$ coordination occurs in almost equal proportions. A structure that satisfies both observations is the $(4 \times 1)$-O arrangement depicted in Figure $6 c$, in which every second row of $-\mathrm{O}$ was removed from the regular $(2 \times 1)$ structure with $0.5 \mathrm{ML}$ coverage. Thus, the $\mathrm{O}$ coverage is 0.25 ML. Nitrogen adsorbates on the $\mathrm{Rh}(111)$ surface prefer hcp 
sites. Therefore, $0.0625 \mathrm{ML}$ of $\mathrm{N}$ was added in hcp sites with a $(4 \times 4)$ periodicity, resulting in an overall $(4 \times 4)-1 \mathrm{~N}-4 \mathrm{O}$ unit cell with an $\mathrm{O} / \mathrm{N}$ ratio of $4: 1$. To verify whether the suggested $(4 \times 4)-1 \mathrm{~N}-0.57 \mathrm{O} / \mathrm{Pt}(111)$ and $(4 \times 4)-1 \mathrm{~N}-4 \mathrm{O} /$ $\mathrm{Rh}(111)$ arrangements are feasible, dedicated DFT and operando STM studies are suggested.

The adsorbate structures concluded from APXPS data raise the question if they exhibit long-range order. Although our APXPS experiment provided solid evidence of the short-range order, additional post-mortem LEED of 1.2 ML Rh/Pt(111) showed a characteristic moire pattern, ${ }^{22}$ confirming also the long-range order of surface oxide retaining after oxidation in (99:1) mixture (Figure S8).

Additionally, a number of surface reconstructions are reported in the literature on ammonia oxidation. ${ }^{13,26}$ One of the most notable reconstructions for PtRh catalysts is the socalled "cauliflower" reconstruction forming at temperatures of $1100-1200 \mathrm{~K}^{26}$ at which volatile $\mathrm{PtO}_{2}$ causes surface restructuring visible to the naked eye. Since the temperature employed in the current study was significantly lower, no such reconstruction was expected at $600 \mathrm{~K}$. Indeed, a post-mortem STM showed flat, featureless $\mathrm{Pt}(111)$ terraces with monoatomic steps (Figure S9).

\section{DISCUSSION}

To understand the behavior of PtRh alloy catalysts used for $\mathrm{NH}_{3}$ oxidation and the effect of Pt alloying with $\mathrm{Rh}$, several model surfaces can be investigated. For example, pure $\mathrm{Rh}(111)$ and $\mathrm{Pt}(111)$ surfaces or crystals with a high step density, ${ }^{8-10,19}$ $\mathrm{Rh}$ films on $\mathrm{Pt}(111)^{25}$ and vice versa, ${ }^{54}$ bulk bimetallic $\mathrm{Pt}_{1-x} \mathrm{Rh}_{x}$ single crystals, ${ }^{20,36,55}$ and supported $\mathrm{PtRh}$ nanoparticles. ${ }^{56-58}$ We hypothesize that thin (0.4-1.2 ML) films of $\mathrm{Rh}$ epitaxially grown on $\mathrm{Pt}(111)$ allow for accurate control of surface alloying as well as for capturing the full spectrum of surface dynamics of $\mathrm{Rh}$ during oxidation and ammonia oxidation at 1 mbar.

Oxidation of Alloys. Comparison of the surfaces with similar Rh coverages of $0.4-0.5 \mathrm{ML}$ during oxidation reveals the strong influence of post-annealing temperature on $\mathrm{Rh}$ surface oxide formation. The APXPS results show that the surface oxide formation occurs on surfaces post-annealed to a temperature below $700 \mathrm{~K}$, while it is hindered for those annealed to $770 \mathrm{~K}$. This establishes that the extent of $\mathrm{Pt}-\mathrm{Rh}$ alloying is dictated by the post-annealing temperature. Higher temperature favors $\mathrm{Rh}$ diffusion to the subsurface and enrichment of $\mathrm{Rh}$ ad-islands with $\mathrm{Pt}$. The more $\mathrm{Pt}$ is within the island, the harder it becomes to form a surface oxide in 1 mbar of $\mathrm{O}_{2}$ at $600 \mathrm{~K}$. Notably, subsurface $\mathrm{Rh}$ is driven back onto the surface in an oxidative environment, and this restores the Rh surface presence completely, even for the sample which had lost $\geq 50 \%$ of its XPS signal during post-annealing (Figure $4 c)$. At a lower annealing temperature of $600 \mathrm{~K}$, the surface of the $\mathrm{Rh}$ 1.2 ML sample is composed mostly of $\mathrm{Rh}$, as confirmed by the formation of an extensive Rh surface oxide. In contrast, the lower-coverage, alloyed $0.4-0.5 \mathrm{ML}$ Rh surfaces did not form a surface oxide due to Pt enrichment but formed a highcoverage oxygen structure- $(2 \sqrt{3} \times 2 \sqrt{3})$ R $30^{\circ}$ (Figure $4 \mathrm{~b}$ ).

Formation of Products. Focusing on the surface structures present in the (99:1) mixture, one can notice that the $(2 \times 2)$ surface structure on $\operatorname{Pt}(111)$, the $(2 \sqrt{3} \times$ $2 \sqrt{3}) \mathrm{R} 30^{\circ}$ surface structure on $0.4 \mathrm{ML} \mathrm{Rh} / \mathrm{Pt}(111)$, and the surface oxide on 1.2 $\mathrm{ML} \mathrm{Rh} / \mathrm{Pt}(111)$ all result in the preferential formation of NO. This leads us to conclude that the presence of highly coordinated $\mathrm{Rh}$ species $(2 \mathrm{O}, 3 \mathrm{O})$ is not strictly required for the formation of NO since the surface with only 10 coordination $[\mathrm{Pt}(111)]$ also behaves similarly.

If we ignore the differences in surface structure and instead compare the absolute amounts of oxygen available on the surfaces, we find that the 1.2 ML Rh preparation in a (50:50) mixture, the bare $\operatorname{Pt}(111)$ sample in a $(99: 1)$ mixture, and the 0.4 ML Rh sample in a (99:1) mixture all feature comparable oxygen coverages of $0.20-0.25 \mathrm{ML}$ (Figure $6 \mathrm{c}$ ). The question arises why these surfaces do not produce the same product distribution in the (99:1) and (50:50) $\mathrm{O}_{2} / \mathrm{NH}_{3}$ mixtures, although they have a comparable oxygen coverage?

Figure 6d,e provides an explanation. In order for the formation of $\mathrm{N}_{2}$ to be favorable, certain critical surface coverage of atomic $\mathrm{N}$ is needed so that the nitrogen atoms can recombine to $\mathrm{N}_{2}$ and desorb. The need for a critical surface concentration of $\mathrm{N}$ was elaborated upon earlier by Aryafar and Zaera, ${ }^{59}$ who suggested that higher $\mathrm{N}$ coverages lead to shorter interatomic distances, allowing slowly diffusing $\mathrm{N}$ atoms to encounter each other and recombine. If this is not achieved, for example, due to a low amount of dosed $\mathrm{NH}_{3}$ (as at 1 mbar with 99:1), the formed atomic $\mathrm{N}$ will encounter more mobile $\mathrm{O}$ atoms, eventually oxidizing and desorbing as NO.

The factors that affect $\mathrm{N}$ coverage are the surface temperature, partial pressure of gases, and adsorption strength $^{60}$ to the catalytic surface. Regarding the latter, surprisingly, the degree of alloying does not affect the observed $\mathrm{N}$ coverage, since in a (50:50) mixture all surfaces exhibit the same nominal coverage of $0.07 \mathrm{ML}$. For example, in the case of the $\mathrm{Pt}(111)$ surface, the stability of adsorbed $\mathrm{N}$ below $650 \mathrm{~K}$ must be the primary reason for $\mathrm{N}_{2}$ production at nearstoichiometric conditions. An increase in temperature will deplete the surface from $-\mathrm{N}$, but not $-\mathrm{O}$, thus driving the selectivity toward NO. A similar result will be achieved by lowering the $\mathrm{NH}_{3}$ partial pressure or decreasing its proportion in the feed, which yields a lower coverage of $\mathrm{N}$. As was previously reported in the literature for close to (50:50) mixing, the switch from $\mathrm{N}_{2}$ to $\mathrm{NO}$ production occurs at around $650-800 \mathrm{~K}$ depending on the catalyst. ${ }^{18}$ More oxygen-rich atmospheres with an $\mathrm{O}_{2} / \mathrm{NH}_{3}$ mixing ratio of (80:20, 90:10) drive the maximum rate of $\mathrm{NO}$ production toward lower temperature, and therefore, the switch in selectivity also occurs at a lower temperature. ${ }^{5}$ It is likely that in the extreme condition of (99:1) mixing, normally employed for $\mathrm{NH}_{3}$ "slip" oxidation, the switch in selectivity may occur at relatively low temperatures, well below $600 \mathrm{~K}$ applied in the current study.

Finally, when comparing the ratio of surface coverage of $\mathrm{N}$ and $\mathrm{O}$ (Figure $6 \mathrm{c})$ in a (50:50) mixture, one can notice a 5fold drop in the $\mathrm{N} / \mathrm{O}$ ratio (1.5 to 0.3 ) when switching between the $\mathrm{Pt}(111)$ surface and the 1.2 $\mathrm{ML} \mathrm{Rh/Pt(111)}$ sample. Based on the earlier argument for N-rich surfaces, this could lead to an increased $\mathrm{N}_{2}$ selectivity on $\mathrm{Pt}(111)$. To answer the question of why an increased - $\mathrm{O}$ coverage on $\mathrm{Rh}$ terminated surface does not lead to higher NO production [vs that at $\mathrm{Pt}(111)]$, further operando and theory investigations are suggested.

\section{CONCLUSIONS}

In order to study alloyed $\mathrm{PtRh}$ surfaces for $\mathrm{NH}_{3}$ oxidation in realistic conditions, we prepared a range of $\mathrm{Pt}(111)$ and alloyed $\mathrm{Rh} / \mathrm{Pt}(111)$ surfaces and studied their behavior in $\mathrm{O}_{2}$ and mixed $\mathrm{O}_{2} / \mathrm{NH}_{3}$ atmospheres at $1 \mathrm{mbar}$ total pressure using operando APXPS. We conclude that the route to control the 
oxidation of the PtRh alloy is by tuning the Rh enrichment at the surface, which is governed by annealing (or preparation) temperature. During the surface oxidation $\mathrm{Rh}$ enrichment in $\mathrm{PtRh}$ allows for more oxygen-rich structures such as (in the order of increasing Rh-enrichment): $(2 \times 2)-1 \mathrm{O}$ on $\mathrm{Pt}(111)<$ $(2 \sqrt{3} \times 2 \sqrt{3})$ R $30^{\circ}-8 \mathrm{O}$ on highly alloyed $\mathrm{PtRh}<$ oxide trilayer on Rh-terminated surface. Thus, the alloyed surfaces, obtained at higher post-annealing temperatures, do not behave like pure Pt or Rh surfaces. Instead, at $600 \mathrm{~K}$ and $1 \mathrm{mbar}$, they act together to form a $(2 \sqrt{3} \times 2 \sqrt{3}) \mathrm{R} 30^{\circ}$ chemisorbed phase. Further oxidation toward a surface oxide trilayer is avoided.

During ammonia oxidation, the surface composition depends strongly on the feed ratio and extent of alloying. In large oxygen excess at an $\mathrm{O}_{2} / \mathrm{NH}_{3}$ mixing ratio of (99:1), the surface composition resembles closely that observed for pure $\mathrm{O}_{2}$ dosing; in this case, the $\mathrm{Rh}$ atoms are highly coordinated to $\mathrm{O}(\mathrm{Rh}-3 \mathrm{O})$ and a $\mathrm{Rh}$ surface oxide is observed. In contrast, in a (50:50) environment, highly coordinated $\mathrm{Rh}$ species largely disappear from the surface; only low $-\mathrm{O}$ coverage phases remain, in which $\mathrm{Rh}$ is coordinated to one oxygen (1O) and two oxygen atoms (2O). It is the extent of alloying that determines the proportion of $2 \mathrm{O}$ coordination, such that $1 \mathrm{O}$ is found for $\mathrm{Pt}$ and Pt-rich PtRh and $2 \mathrm{O}$ for more Rh-rich coverages.

The two feeding regimes result in the two opposite product distributions at $1 \mathrm{mbar}$ at $600 \mathrm{~K}$, that is $\mathrm{NO}$ in the oxygen-rich mix and $\mathrm{N}_{2}$ otherwise. The route to $\mathrm{N}_{2}$ production relies on a certain critical surface coverage of atomic $\mathrm{N}$, which has enough residence time to meet and recombine. If the $\mathrm{N}$ coverage is too low, further oxidation to NO occurs.

Finally, from direct spectroscopic measurements, we conclude that $\mathrm{Rh}$-enrichment not only enables higher-density oxygen structures in PtRh alloys, but it also is capable of enhancing the proportion of the main product, whether it is $\mathrm{NO}$ or $\mathrm{N}_{2}$. We foresee a constant feedback loop between kinetic data from classic catalysis and surface-sensitive operando experiments to advance the rational search for optimal bimetallic alloyed catalysts.

\section{ASSOCIATED CONTENT}

\section{SI Supporting Information}

The Supporting Information is available free of charge at https://pubs.acs.org/doi/10.1021/acscatal.1c00956.

Additional APXPS, LEED, STM, and QMS data (PDF).

\section{AUTHOR INFORMATION}

\section{Corresponding Authors}

Oleksii Ivashenko - Centre for Materials Science and Nanotechnology, Department of Chemistry, University of Oslo, 0315 Oslo, Norway; (1) orcid.org/0000-0002-32654506; Email: oleksii.ivashenko@smn.uio.no

Anja O. Sjåstad - Centre for Materials Science and Nanotechnology, Department of Chemistry, University of Oslo, 0315 Oslo, Norway; Email: a.o.sjastad@kjemi.uio.no

\section{Authors}

Niclas Johansson - MAX IV Laboratory, Lund University, 22100 Lund, Sweden

Christine Pettersen - Centre for Materials Science and Nanotechnology, Department of Chemistry, University of Oslo, 0315 Oslo, Norway
Martin Jensen - Centre for Materials Science and Nanotechnology, Department of Chemistry, University of Oslo, 0315 Oslo, Norway

Jian Zheng - Centre for Materials Science and Nanotechnology, Department of Chemistry, University of Oslo, 0315 Oslo, Norway; $\odot$ orcid.org/0000-0001-81119211

Joachim Schnadt - MAX IV Laboratory, Lund University, 22100 Lund, Sweden; Division of Synchrotron Radiation Research, Department of Physics, Lund University, 22100 Lund, Sweden; 10 orcid.org/0000-0001-9375-831X

Complete contact information is available at: https://pubs.acs.org/10.1021/acscatal.1c00956

\section{Notes}

The authors declare no competing financial interest.

\section{ACKNOWLEDGMENTS}

The authors thank Dr. S. Blomberg and Prof. A. Beretta for fruitful discussions. The authors appreciate instrumental support of Dr. S. Zhu (Max IV) during APXPS and help from Dr. N. Vinogradov in acquiring the post-mortem STM data (SPM lab, Max IV). O.I. and J.Z. acknowledge, respectively, support by the industrial Catalysis Science and Innovation Centre (iCSI) and the ASCAT-project, which receives financial support from the Research Council of Norway (contract nos. 237922 and 247753). A.O.S., J.S., and J.Z. acknowledge the support from the Interreg funding (20200417). The authors acknowledge the MAX IV Laboratory for time on the HIPPIE beamline under proposal no. 20180352. Research conducted at MAX IV, a Swedish national user facility, is supported by Vetenskapsrådet (Swedish Research Council, VR) under contract 2018-07152, Vinnova (Swedish Governmental Agency for Innovation Systems) under contract 2018-04969 and Formas under contract 2019-02496.

\section{REFERENCES}

(1) Walker, A. Future Challenges and Incoming Solutions in Emission Control for Heavy Duty Diesel Vehicles. Top. Catal. 2016, 59, 695-707.

(2) Bergene, E.; Tronstad, O.; Holmen, A. Surface Areas of Pt-Rh Catalyst Gauzes Used for Ammonia Oxidation. J. Catal. 1996, 160, 141-147.

(3) Zeng, Y.; Imbihl, R. Structure sensitivity of ammonia oxidation over platinum. J. Catal. 2009, 261, 129-136.

(4) Mieher, W. D.; Ho, W. Thermally activated oxidation of NHs on $\mathrm{Pt}(111)$ : intermediate species and reaction mechanisms. Surf. Sci. 1995, 322, 151-167.

(5) Rafti, M.; Lovis, F.; Imbihl, R. The O2 + NH3 Reaction Over $\mathrm{Rh}$ (110): Steady State Kinetics and Oscillatory Behavior. Catal. Lett. 2012, 142, 16-21.

(6) Rafti, M.; Uecker, H.; Lovis, F.; Krupennikova, V.; Imbihl, R. Traveling interface modulations in the $\mathrm{NH} 3+\mathrm{O} 2$ reaction on a $\mathrm{Rh}(110)$ surface. Phys. Chem. Chem. Phys. 2012, 14, 5260-5264.

(7) Gland, J.; Korchak, V. N. Ammonia oxidation on a stepped platinum single-crystal surface. J. Catal. 1978, 53, 9-23.

(8) Weststrate, C.; Bakker, J.; Rienks, E.; Vinod, C.; Matveev, A.; Gorodetskii, V.; Nieuwenhuys, B. Ammonia oxidation on $\mathrm{Pt}(410)$. J. Catal. 2006, 242, 184-194.

(9) Scheibe, A.; Günther, S.; Imbihl, R. Selectivity Changes Due to Restructuring of the $\mathrm{Pt}(533)$ Surface in the $\mathrm{NH} 3+\mathrm{O} 2$ Reaction. Catal. Lett. 2003, 86, 33-37. 
(10) Scheibe, A.; Lins, U.; Imbihl, R. Kinetics of ammonia oxidation on stepped platinum surfaces. I. Experimental results. Surf. Sci. 2005, 577, $1-14$.

(11) Westerström, R.; Wang, J. G.; Ackermann, M. D.; Gustafson, J.; Resta, A.; Mikkelsen, A.; Andersen, J. N.; Lundgren, E.; Balmes, O.; Torrelles, X.; Frenken, J. W. M.; Hammer, B. Structure and reactivity of a model catalyst alloy under realistic conditions. J. Phys.: Condens. Matter 2008, 20, 184018.

(12) Bradley, J. M.; Hopkinson, A.; King, D. A. Control of a Biphasic Surface Reaction by Oxygen Coverage: The Catalytic Oxidation of Ammonia over Pt $\{100\}$. J. Phys. Chem. 1995, 99, 17032-17042.

(13) Kraehnert, R.; Baerns, M. Kinetics of ammonia oxidation over Pt foil studied in a micro-structured quartz-reactor. Chem. Eng. J. 2008, 137, 361-375.

(14) Offermans, W. K.; Jansen, A. P. J.; van Santen, R. A. Ammonia activation on platinum $\{111\}$ : A density functional theory study. Surf. Sci. 2006, 600, 1714-1734.

(15) Popa, C.; van Santen, R. A.; Jansen, A. P. J. Density-Functional Theory Study of NHx Oxidation and Reverse Reactions on the $\mathrm{Rh}(111)$ Surface. J. Phys. Chem. C 2007, 111, 9839-9852.

(16) Imbihl, R.; Scheibe, A.; Zeng, Y. F.; Günther, S.; Kraehnert, R.; Kondratenko, V. A.; Baerns, M.; Offermans, W. K.; Jansen, A. P. J.; van Santen, R. A. Catalytic ammonia oxidation on platinum: mechanism and catalyst restructuring at high and low pressure. Phys. Chem. Chem. Phys. 2007, 9, 3522-3540.

(17) Offermans, W. K.; Jansen, A. P. J.; van Santen, R. A.; NovellLeruth, G.; Ricart, J. M.; Pérez-Ramírez, J. Ammonia Dissociation on $\operatorname{Pt}\{100\}$, Pt $\{111\}$, and Pt $\{211\}$ : A Comparative Density Functional Theory Study. J. Phys. Chem. C 2007, 111, 17551-17557.

(18) Baerns, M.; Imbihl, R.; Kondratenko, V.; Kraehnert, R.; Offermans, W.; Vansanten, R.; Scheibe, A. Bridging the pressure and material gap in the catalytic ammonia oxidation: structural and catalytic properties of different platinum catalysts. J. Catal. 2005, 232, 226-238.

(19) Günther, S.; Scheibe, A.; Bluhm, H.; Haevecker, M.; Kleimenov, E.; Knop-Gericke, A.; Schlögl, R.; Imbihl, R. In Situ Xray Photoelectron Spectroscopy of Catalytic Ammonia Oxidation over a Pt(533) Surface. J. Phys. Chem. C 2008, 112, 15382-15393.

(20) Resta, A.; Hejral, U.; Blomberg, S.; Albertin, S.; Vlad, A.; Garreau, Y.; Chatelier, C.; Venturini, F.; Ferrer, P.; Held, G.; Grinter, D.; Lundgren, E.; Coati, A. Ammonia Oxidation over a Pt25Rh75(001) Model Catalyst Surface: An Operando Study. J. Phys. Chem. C 2020, 124, 22192-22199.

(21) Blomberg, S.; Lundgren, E.; Westerström, R.; Erdogan, E.; Martin, N. M.; Mikkelsen, A.; Andersen, J. N.; Mittendorfer, F.; Gustafson, J. Structure of the Rh2O3(0001) surface. Surf. Sci. 2012, 606, 1416-1421.

(22) Gustafson, J.; Mikkelsen, A.; Borg, M.; Lundgren, E.; Köhler, L.; Kresse, G.; Schmid, M.; Varga, P.; Yuhara, J.; Torrelles, X.; Quirós, C.; Andersen, J. N. Self-Limited Growth of a Thin Oxide Layer on Rh(111). Phys. Rev. Lett. 2004, 92, 126102.

(23) Gustafson, J.; Balmes, O.; Zhang, C.; Shipilin, M.; Schaefer, A.; Hagman, B.; Merte, L. R.; Martin, N. M.; Carlsson, P.-A.; Jankowski, M.; Crumlin, E. J.; Lundgren, E. The Role of Oxides in Catalytic CO Oxidation over Rhodium and Palladium. ACS Catal. 2018, 8, 44384445.

(24) Farber, R. G.; Turano, M. E.; Killelea, D. R. Identification of Surface Sites for Low-Temperature Heterogeneously Catalyzed CO Oxidation on $\mathrm{Rh}(111)$. ACS Catal. 2018, 8, 11483-11490.

(25) Zheng, J.; Ivashenko, O.; Fjellvåg, H.; Groot, I. M. N.; Sjåstad, A. O. Roadmap for Modeling $\mathrm{RhPt} / \mathrm{Pt}(111)$ Catalytic Surfaces. J. Phys. Chem. C 2018, 122, 26430-26437.

(26) Fjellvåg, A. S.; Waller, D.; Skjelstad, J.; Sjåstad, A. O. Grain Reconstruction of Palladium and Palladium-Nickel Alloys for Platinum Catchment. Johnson Matthey Technol. Rev. 2019, 63, 236246.

(27) Zhu, S.; Scardamaglia, M.; Kundsen, J.; Sankari, R.; Tarawneh, H.; Temperton, R.; Pickworth, L.; Cavalca, F.; Wang, C.; Tissot, H.; Weissenrieder, J.; Hagman, B.; Gustafson, J.; Kaya, S.; Lindgren, F.;
Källquist, I.; Maibach, J.; Hahlin, M.; Boix, V.; Gallo, T.; Rehman, F.; D’Acunto, G.; Schnadt, J.; Shavorskiy, A. HIPPIE: a new platform for ambient-pressure X-ray photoelectron spectroscopy at the MAX IV Laboratory. J. Synchrotron Radiat. 2021, 28, 624-636.

(28) Schnadt, J.; Knudsen, J.; Andersen, J. N.; Siegbahn, H.; Pietzsch, A.; Hennies, F.; Johansson, N.; Mårtensson, N.; Öhrwall, G.; Bahr, S.; Mähl, S.; Schaff, O. The new ambient-pressure X-ray photoelectron spectroscopy instrument at MAX-lab. J. Synchrotron Radiat. 2012, 19, 701-704.

(29) Ganduglia-Pirovano, M. V.; Scheffler, M.; Baraldi, A.; Lizzit, S.; Comelli, G.; Paolucci, G.; Rosei, R. Oxygen-induced Rh $3 \mathrm{~d}_{5 / 2}$ surface core-level shifts on $\mathrm{Rh}(111)$. Phys. Rev. B: Condens. Matter Mater. Phys. 2001, 63, 205415.

(30) LISE laboratory of the Facultes Universitaires Notre-Dame de la Paix, N., Belgium, Least-Squares Curve Fitting Program Winspec.

(31) Yeh, J. J.; Lindau, I. Atomic subshell photoionization cross sections and asymmetry parameters: $1 \leqslant Z \leqslant 103$. At. Data Nucl. Data Tables 1985, 32, 1-155.

(32) Schnadt, J.; Knudsen, J.; Johansson, N. Present and new frontiers in materials research by ambient pressure x-ray photoelectron spectroscopy. J. Phys.: Condens. Matter 2020, 32, 413003.

(33) Horcas, I.; Fernández, R.; Gómez-Rodríguez, J. M.; Colchero, J.; Gómez-Herrero, J.; Baro, A. M. WSXM: A software for scanning probe microscopy and a tool for nanotechnology. Rev. Sci. Instrum. 2007, 78, 013705.

(34) Blomberg, S.; Westerström, R.; Martin, N. M.; Lundgren, E.; Andersen, J. N.; Messing, M. E.; Gustafson, J. A high pressure X-ray photoelectron spectroscopy study of oxidation and reduction of $\mathrm{Rh}(100)$ and Rh nanoparticles. Surf. Sci. 2014, 628, 153-158.

(35) Gustafson, J.; Borg, M.; Mikkelsen, A.; Gorovikov, S.; Lundgren, E.; Andersen, J. N. Identification of Step Atoms by High Resolution Core Level Spectroscopy. Phys. Rev. Lett. 2003, 91, 056102 .

(36) Hebenstreit, E. L. D.; Hebenstreit, W.; Schmid, M.; Varga, P. Pt25Rh75(111), (110), and (100) studied by scanning tunnelling microscopy with chemical contrast. Surf. Sci. 1999, 441, 441-453.

(37) Miller, D. J.; Öberg, H.; Kaya, S.; Sanchez Casalongue, H.; Friebel, D.; Anniyev, T.; Ogasawara, H.; Bluhm, H.; Pettersson, L. G. M.; Nilsson, A. Oxidation of $\mathrm{Pt}(111)$ under Near-Ambient Conditions. Phys. Rev. Lett. 2011, 107, 195502.

(38) Puglia, C.; Nilsson, A.; Hernnäs, B.; Karis, O.; Bennich, P.; Mårtensson, N. Physisorbed, chemisorbed and dissociated $\mathrm{O} 2$ on $\mathrm{Pt}(111)$ studied by different core level spectroscopy methods. Surf. Sci. 1995, 342, 119-133.

(39) Köhler, L.; Kresse, G.; Schmid, M.; Lundgren, E.; Gustafson, J.; Mikkelsen, A.; Borg, M.; Yuhara, J.; Andersen, J. N.; Marsman, M.; Varga, P. High-Coverage Oxygen Structures on $\mathrm{Rh}(111)$ : Adsorbate Repulsion and Site Preference Is Not Enough. Phys. Rev. Lett. 2004, 93, 266103.

(40) Zhu, Z.; Melaet, G.; Axnanda, S.; Alayoglu, S.; Liu, Z.; Salmeron, M.; Somorjai, G. A. Structure and Chemical State of the $\mathrm{Pt}(557)$ Surface during Hydrogen Oxidation Reaction Studied by in Situ Scanning Tunneling Microscopy and X-ray Photoelectron Spectroscopy. J. Am. Chem. Soc. 2013, 135, 12560-12563.

(41) Siegbahn, K.; Nordling, C.; Johansson, G.; Hedman, J.; Hedén, P. F.; Hamrin, K.; Gelius, U.; Bergmark, T.; Werme, L. O.; Manne, R. ESCA: Applied to Free Molecules; North-Holland Publishing Company, 1969.

(42) Kiskinova, M.; Pirug, G.; Bonzel, H. P. Adsorption and decomposition of $\mathrm{H} 2 \mathrm{O}$ on a K-covered $\mathrm{Pt}(111)$ surface. Surf. Sci. $1985,150,319-338$.

(43) Scheibe, A.; Hinz, M.; Imbihl, R. Kinetics of ammonia oxidation on stepped platinum surfaces: II. Simulation results. Surf. Sci. 2005, 576, 131-144.

(44) Ueda, K.; Isegawa, K.; Amemiya, K.; Mase, K.; Kondoh, H. Operando NAP-XPS Observation and Kinetics Analysis of NO Reduction over $\mathrm{Rh}(111)$ Surface: Characterization of Active Surface and Reactive Species. ACS Catal. 2018, 8, 11663-11670. 
(45) Zhu, J. F.; Kinne, M.; Fuhrmann, T.; Denecke, R.; Steinrück, H.-P. In situ high-resolution XPS studies on adsorption of NO on Pt(111). Surf. Sci. 2003, 529, 384-396.

(46) Zhang, X.; Ptasinska, S. Evolution of Surface-Assisted Oxidation of GaAs (100) by Gas-Phase N2O, NO, and O2 under Near-Ambient Pressure Conditions. J. Phys. Chem. C 2015, 119, 262-270.

(47) Ma, H.; Schneider, W. F. DFT and microkinetic comparison of $\mathrm{Pt}, \mathrm{Pd}$ and Rh-catalyzed ammonia oxidation. J. Catal. 2020, 383, 322330.

(48) Pignet, T.; Schmidt, L. D. Kinetics of NH3 oxidation on Pt, Rh, and Pd. J. Catal. 1975, 40, 212-225.

(49) Kiss, J.; Lennon, D.; Jo, S. K.; White, J. M. Photoinduced dissociation and desorption of nitrous oxide on a platinum(111) surface. J. Phys. Chem. 1991, 95, 8054-8059.

(50) Hosaka, K.; Adachi, J.; Takahashi, M.; Yagishita, A. N 1s photoionization cross sections of nitric oxide molecules in the shape resonance region. J. Phys. B: At., Mol. Opt. Phys. 2003, 36, 4617-4629.

(51) Shimada, T.; Mun, B. S.; Nakai, I. F.; Banno, A.; Abe, H.; Iwasawa, Y.; Ohta, T.; Kondoh, H. Irreversible Change in the NO Adsorption State on $\mathrm{Pt}(111)$ under High Pressure Studied by APXPS, NEXAFS, and STM. J. Phys. Chem. C 2010, 114, 17030-17035.

(52) Kiskinova, M.; Pirug, G.; Bonzel, H. P. No adsorption on Pt(111). Surf. Sci. 1984, 136, 285-295.

(53) Requejo, F.; Hebenstreit, E. L. D.; Ogletree, D. F.; Salmeron, M. An in situ XPS study of site competition between $\mathrm{CO}$ and NO on $\mathrm{Rh}(111)$ in equilibrium with the gas phase. J. Catal. 2004, 226, 8387.

(54) Duisberg, M.; Dräger, M.; Wandelt, K.; Gruber, E. L. D.; Schmid, M.; Varga, P. High temperature growth of $\mathrm{Pt}$ on the $\mathrm{Rh}(111)$ surface. Surf. Sci. 1999, 433-435, 554-558.

(55) Platzgummer, E.; Sporn, M.; Koller, R.; Forsthuber, S.; Schmid, M.; Hofer, W.; Varga, P. Temperature-dependent segregation on Pt25Rh75(111) and (100). Surf. Sci. 1999, 419, 236-248.

(56) Kalyva, M.; Wragg, D. S.; Fjellvåg, H.; Sjåstad, A. O. Engineering Functions into Platinum and Platinum-Rhodium Nanoparticles in a One-Step Microwave Irradiation Synthesis. Chemistryopen 2017, 6, 273-281.

(57) Tao, F.; Grass, M. E.; Zhang, Y.; Butcher, D. R.; Aksoy, F.; Aloni, S.; Altoe, V.; Alayoglu, S.; Renzas, J. R.; Tsung, C.-K.; Zhu, Z.; Liu, Z.; Salmeron, M.; Somorjai, G. A. Evolution of Structure and Chemistry of Bimetallic Nanoparticle Catalysts under Reaction Conditions. J. Am. Chem. Soc. 2010, 132, 8697-8703.

(58) Hejral, U.; Franz, D.; Volkov, S.; Francoual, S.; Strempfer, J.; Stierle, A. Identification of a Catalytically Highly Active Surface Phase for CO Oxidation over PtRh Nanoparticles under Operando Reaction Conditions. Phys. Rev. Lett. 2018, 120, 126101.

(59) Aryafar, M.; Zaera, F. Isothermal Kinetic Study of the Decomposition of Nitric Oxide over Rh(111) Surfaces. J. Catal. 1998, 175, 316-327.

(60) Miller, S. D.; İnoğlu, N.; Kitchin, J. R. Configurational correlations in the coverage dependent adsorption energies of oxygen atoms on late transition metal fcc(111) surfaces. J. Chem. Phys. 2011, 134, 104709. 